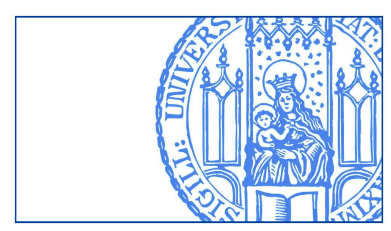

Cao, Jin:

Illiquidity, insolvency, and banking regulation

Munich Discussion Paper No. 2010-13

Department of Economics

University of Munich

Volkswirtschaftliche Fakultät

Ludwig-Maximilians-Universitä† München

Online at https://doi.org/10.5282/ubm/epub. 11370 


\title{
Illiquidity, insolvency, and banking regulation *
}

\author{
Jin $\mathrm{Cao}^{\mathrm{a}, \mathrm{b}, *}$, \\ ${ }^{a}$ Munich Graduate School of Economics (MGSE), Germany \\ ${ }^{\mathrm{b}}$ Department of Economics, University of Munich, D-80539 Munich, Germany
}

\begin{abstract}
This paper provides a compact framework for banking regulation analysis in the presence of uncertainty between systemic liquidity and solvency shocks. Extending the work by Cao \& Illing (2009a, b), it is shown that systemic liquidity shortage arises endogenously as part of the inferior mixed strategy equilibrium. The paper compares different traditional regulatory policies which intend to fix the inefficiencies, and argues that the co-existence of illiquidity and insolvency problems adds extra cost for banking regulation and makes some schemes that are optimal under pure illiquidity risks (such as liquidity regulation with lender of last resort policy) fail. The regulatory cost can be minimized by combining the advantages of several instruments.

JEL classification: E5, G21, G28
\end{abstract}

Key words: liquidity risk, insolvency risk, liquidity regulation, equity requirement

\footnotetext{
^ First version: July 2009. This version: November 2009. A very preliminary version. The author thanks Gerhard Illing and Ted Temzelides for very useful comments.

* Corresponding author. Seminar für Makroökonomie, Ludwig-MaximiliansUniversität München, Ludwigstrasse 28/015 (Rgb.), D-80539 Munich, Germany. Tel.: +49 892180 2136; fax: +49 89218013521 .

Email address: jin.cao@lrz. uni-muenchen .de (Jin Cao).
} 


\section{Introduction}

In the banking literature, illiquidity and insolvency problems have been intensively studied for decades. Illiquidity means that one financial institution is not able to meet its short term liability via monetizing the future gains from its long term projects - in other words, there's a mismatch between the time when the long term projects return and the time when its liability is due, i.e. it's "cash flow trapped" but "balance sheet solvent". In contrast, insolvency of a financial institution generally means that liabilities exceed assets in its balance sheet, i.e. it is not able to meet due liabilities even by perfectly monetizing the future gains from its long term projects. Existing banking models usually focus on either problem. If a financial firm's ailment is diagnosed to be one of them, the solution is then (at least intuitively) clear. For example, illiquid banks may be bailed out by central bank's liquidity injection (against their illiquid assets "good" collateral, see Cao \& Illing, 2009a, b), and insolvent banks have to be closed down in order to avoid contagion (see Freixas, Parigi and Rochet, 2004).

Since mid-2007, the world has seen one of the worst financial crises in history, which has stolen millions of jobs and held the entire global economy to ransom. As is observed in the past two years, one prominent feature about this crisis is the ambiguity in the financial institutions' health, especially the daunting question whether the problem for the large banks is illiquidity or insolvency. Financial innovation in the past two decades doesn't only help improve market efficiency, but also creates high complexity (hence, asymmetric information) which blurs the boundary between illiquidity and insolvency. The over complicated financial products, as Gorton (2009) states, finally "could not be penetrated by most investors or counterparties in the financial system to determine the location and size of the risks." For example, subprime mortgages, a financial innovation from which the current crisis broke out, were designed to finance riskier long-term borrowers via shortterm funding. So when the trend of continuing US house price appreciation started to stagger and giant investment banks ran into trouble, the trouble 
seemed to be a mere illiquidity problem — as long as house prices were to increase in the future, the long-term yields of subprime mortgage-related assets would be juicy as well. However, since the location and size of the risks in these complicated financial products could not be fully perceived even by the designer banks themselves, there was a probability that these financial institutions were insolvent. In this vague scenario banks could hardly get sufficient liquidity from market and the crisis erupted.

These events bring new challenges to both market practitioners and banking regulators. If there's no ambiguity between illiquidity and insolvency, conventional wisdom works well: if the problem is just illiquidity, then liquidity regulation works perfectly - banks can get enough liquidity from the central bank putting their long-term assets as collateral, since the high yields from these assets will return in the future with certainty. If the problem is insolvency, equity holding can be a self-sufficient solution for the banks to eliminate their losses. However, if there's uncertainty about the banks' trouble, things become complicated — banks cannot get enough liquidity because the collateral, in the presence of insolvency risk, is no longer considered to be good. Therefore, liquidity regulation may fail. On the other hand, equity requirements may be inefficient as well because the co-existence of the two problems make equity holding even costlier. This paper hopes to shed some light on understanding the market failure and designing proper regulatory rules with a compact and flexible model.

\subsection{Summary of the paper}

In this paper, banks are intermediaries financing entrepreneurs' short-term (safe) and long-term (risky) projects via short-term deposit contracts, as in Diamond \& Rajan (2006). Illiquidity is modelled in Cao \& Illing (2009a): some fraction of risky projects turns out to be realized late. The aggregate share of late projects is endogenous; it depends on the incentives of financial intermediaries to invest in risky, illiquid projects. This endogeneity captures 
the feedback from liquidity provision to risk taking incentives of financial intermediaries.

Unlike in models with pure illiquidity or insolvency problems, in the intermediate period the market participants only observe the aggregate amount of early returns from the risky projects. However, they don't know whether these risky assets are just illiquid (i.e. the majority of high yield risky projects will return late), or whether the banks are insolvent (i.e. the substantial amount of the risky projects will fail in the next period). The introduction of such ambiguity has both significant impacts on equilibrium outcomes and new implications for banking regulation.

Given the same structure of the banking game as in Cao \& Illing (2008, 2009a), the equilibria in this extended model are similar: two types of pure strategy equilibria - the banks coordinate to be risky when the sun always shines and be prudent when it always rains, and a mixed strategy equilibrium for intermediate $\pi$. However, the gap between the expected return from the risky projects in the good state and that in the bad state gets higher with the uncertainty on the true problem - asset price is more inflated in the good state because of the probability that the risky assets are just illiquid, while asset price is more depressed in the bad state because of the probability that the banks are going to be insolvent. The bigger gap makes the interval for mixed strategy equilibrium wider in current setting, making free-riding more attractive (more excessive liquidity supply when time is good).

We derive some new insights for banking regulation. The solution for the pure illiquidity risk case, as proposed in Cao \& Illing (2009b), is to have ex ante liquidity requirements with ex post conditional bailout. This is not sufficient now. The reason is simple: because the central bank doesn't have superior knowledge to that of market participants, i.e. it isn't able to distinguish between illiquidity and insolvency risks, the value of the banks' collateral in the bad state cannot be as high as that at that in the good state. Therefore, the banks cannot get sufficient liquidity from the central bank in 
the bad state even they do observe the ex ante liquidity requirement. A bank run is, thus, not avoided any more.

This finding suggests that the additional insolvency problem implies an extra cost for stabilizing the financial system, i.e. the regulator needs extra resources to hedge against the insolvency risk. Therefore, a counter-cyclical deposit insurance mechanism will work. The proposal is as follows: the banks have to be taxed away part of their revenue in the good state and the taxation revenue can be used to cover the cost in central bank's liquidity provision in the bad state.

It is worth mentioning equity requirements, as typical solution in the case of pure insolvency risk, is suboptimal as well. The co-existence of two banking plagues means higher capital ratio, hence higher cost, should be imposed for banking industry.

Since it's hard to catch two rabbits at the same time, it might be optimal to combine the advantages of several instruments. A hybrid regulatory scheme is therefore proposed in this paper, allowing liquidity regulation to discourage the inferior mixed strategy equilibrium (which leads to liquidity shortage) and equity requirement to absorb the loss from insolvency.

\subsection{Review of literature}

This paper is an extension of the baseline model from the previous work by Cao \& Illing $(2008,2009 a, 2009 b)$. It has been shown that when there is only pure illiquidity risk, there's an incentive for a financial institution to free-ride on liquidity provision from the others, resulting in excessively low liquidity in bad states. Since illiquidity is the only risk, conditional (with ex ante liquidity requirements for banks' entry to the financial market), a liquidity injection from the central bank fully eliminates the risk of bank runs when bad states are less likely, and the outcome of such conditional bailout policy dominates that of capital requirements since the banks have 
to incur a substantially high cost of holding equity in order to fully stabilize the system. However, one may ask what happens if there's an additional risk of insolvency. Indeed, when insolvency is mixed with illiquidity and market participants cannot distinguish between the two, banks would have difficulties in raising sufficient liquidity using their assets as collateral. This may have profound impacts on both equilibrium outcomes and policy implications, and exploring these issues is the main task of this paper.

This paper contributes to the existing literature in two respects:

(1) This paper addresses the systemic liquidity risk as an endogenous phenomenon arising from the joint illiquidity-insolvency problem;

(2) Central bank intervention and banking regulation are examined under nominal, instead of real, contracts.

Although illiquidity and insolvency problems respectively have been intensively studied in the banking literature, the endogenous systemic liquidity risk arising from the co-existence of both problems has been rarely investigated. Most past works that analyze these two problems in one model mainly focus on how banking crises evolve, rather than why the banking industry arrives at the brink of collapse. Therefore, liquidity shortage is usually introduced as an exogenous shock, instead of a strategic outcome. For example, Freixas, Parigi and Rochet $(2000,2004)$ model systemic liquidity risk out of coordinative failure from the interbank market. In their model, a banking crisis may be triggered by an exogenous insolvency shock; therefore, closing insolvent banks helps cut off the contagion chain and save the system. Taking liquidity risk as (partially) exogenously given works well for understanding the development of banking crisis, however, one has to be cautious when applying these models on banking regulation. As is stated in Acharya (2009), "... Such partial equilibrium approach has a serious shortcoming from the standpoint of understanding sources of, and addressing, inefficient systemic risk... " In other words, if we admit that it is equally important to establish proper regulatory rules ex ante as it is to bailout the failing banks ex post, it should be equally crucial to ask what causes the fail- 
ure as to tell how severe the crisis can be, i.e. systemic liquidity risk should be an endogenous phenomenon.

It seems that an increasing number of recent works start analyzing endogenous incentives for systemic risk. Acharya (2009) and Acharya \& Yorulmazer (2008) define such incentive as the correlation of portfolio selection, i.e. when the return of a bank's investment has a "systemic factor", the failure of one bank conveys negative information about this factor, which makes the market participants worry about the health of the entire banking industry, increasing the bank's probability to fail. The concern of such "informational spillover" induces the banks to herd ex ante, leading to an inefficiently high correlation in the banks' portfolio choices. These insights are similar in spirit (but quite different in modelling) as in this paper (for example, the inefficiently high correlation corresponds to the mixed strategy equilibrium and public information about the early returns means perfect informational spillover); however, since illiquidity problem is not explicitly modelled in their works, liquidity regulation doesn't play any role (in contrast to this paper).

Recent endogenous approaches to modelling systemic liquidity risk include Wagner (2009), in which inefficiency comes from the externalities of bank runs), Korinek (2008, in which inefficiency comes from the fact that financial institutions don't internalize the impact of asset prices on the production sector), etc. However, to the best of my knowledge, works addressing joint illiquidity-insolvency problem and its impact on macro policy still seem to be rare, if not absent. In this sense, this paper contributes to understanding this new feature and the lessons for banking regulation.

The mostly closely related work is probably the model considered in Bolton, Santos and Scheinkman (2009a, a.k.a. BSS as in the following). The feature that the market participants can hardly distinguish between illiquidity and insolvency is captured in their model, while they mainly focus on the supply side of liquidity, i.e. liquidity from financial institutions' own cash reserve (inside liquidity) or from the proceeds from asset sales to the other investors 
with longer time preference (outside liquidity), and the timing perspective of liquidity trading. This paper takes BSS's view that (outside) liquidity shortage arises from the banks' coordinative failure, but the timing of liquidity trading is not going to be my focus. Rather, I provide a different explanation of systemic liquidity risk, i.e. liquidity under-provision may come from the banks' incentive of free-riding on each others' liquidity supply, which is not covered in BSS (in which they restrict attentions to pure strategy equilibria); and clear-cut results from a more compact and flexible model in this paper lead to clear-cut policy implications. What's more, since financial contracts in BSS are real, they (BSS, 2009b) conclude that efficiency can be restored by central banks' credible supporting (real) asset prices. However, in reality, instead of redirecting real resources to the financial sector, central banks can only increase the supply of fiat money and support the nominal prices. If we take this into account, nominal liquidity injection from central banks may crowd out market liquidity supply without improving efficiency, therefore policy makers should take a more careful view on designing regulatory rules and bailout policies.

In the banking literature, a related inside-outside liquidity approach has been explored in Holmström and Tirole $(1998,2008)$, etc. (although their focuses and methodologies are quite different from those in this paper). These papers argue that since private liquidity supply is inefficient, public provision of emergency (real) liquidity as a pure public good improves allocations in the presence of aggregate shocks. However, central banks usually lack the capability of redirecting the economy's real resources to the financial sector via lump sum taxation; instead, more likely they can only achieve redistribution through nominal instruments. This view is in line with Allen \& Gale (1998), in which public liquidity intervention works through nominal contracts and the price level is adjusted via cash-in-themarket principle. Diamond \& Rajan (2006) explores this mechanism further. However, unlike this paper it focuses on monetary policy in banking crisis - liquidity shocks are, thus, taken as exogenously given. 


\subsection{Structure of the paper}

Section 2 presents the baseline model with real deposit contracts. Section 2.1 shows the equilibrium when liquidity and solvency shocks are both deterministic. Then SECTION 2.2 extends the results to the case of uncertainty in the types of shocks. Section 2.3 describes the equilibria of such laissezfaire economy. The failure of liquidity regulation is analyzed in SECTION 3.1, and an alternative scheme with additional taxation is proposed. It is shown in SeCTION 4 that equity requirements become too costly in the presence of both illiquidity and insolvency problems, therefore an improved regulatory scheme combining liquidity regulation and minimum level of capital ratio is discussed. Section 5 concludes.

\section{The model}

In this section the deposit contracts are restricted to be real, i.e., the central bank as a fiat money issuer is absent in the game. The model is almost the same as that from Cao \& Illing (2008); the differences are (1) the payoff structure of the risky assets; (2) the information. The basic elements of the game are summarized in Table 1 and Fig. 1

Agents with different time preferences There are three types of risk neutral agents: a continuum of investors (each endowed with unit of resources), $N$ banks (operated by bank managers or bankers, engaging in Bertrand competition) and a continuum of entrepreneurs. Impatient investors want to consume one period after investing their endowments, while entrepreneurs and bank managers are indifferent between consuming early or late;

Technologies Investors only have access to an inferior storage technology (therefore, as described in Cao \& Illing (2008) they will take the deposit contract if the expected gross return rate from the deposit is higher than 1 ). There are two types of entrepreneurs with different projects: safe (liquid) 
Table 1

The basic elements of the extended model: Agents, technologies, and preferences

Investors

- Unit $t=0$ endowment - stored or invested in projects;

- Investors want to consume at $t=1$.

Entrepreneurs

- With type 1 project

- Return $R_{1}>1$, safely realized at $t=1$;

- With type 2 project

- Highest return $R_{2}>R_{1}$, risky. It may return at $t=1$,

- but also may be delayed to $t=2$, or

- fail with zero return.

Banks

- Engage in Bertrand competition;

- Expertise to collect $0<\gamma<1$ from projects return;

- Offer deposit contracts

— Commitment device not to abuse the expertise, and

— Making banking industry fragile;

- Risk of bank runs: poor liquidation return $0<c<1$.

projects returning $R_{1}>1$ for sure at $t=1$, risky (illiquid) projects as explained later. Bank managers have the expertise in collecting a share $\gamma$ of the projects' return - a motivation for intermediation;

Timing At $t=0$ banks compete for investors by providing a take-it-orleave-it deposit contract $\left(\alpha_{i}, d_{0}^{i}\right)$ in which $\alpha_{i}$ is the share of bank $i$ 's investments on safe projects and $d_{0}^{i}$ the promised $t=1$ return for investors. The illiquid projects' riskiness is unknown at $t=0$ but partially revealed at $t=\frac{1}{2}$, at which time the investors decide whether to run the banks or wait till $t=1$. In the case of a run, both safe and risky projects have to be 
liquidated with a poor return $0<c<1$;

Limited liability All the financial contracts only have to be met with the debtors' entire assets. For the deposit contracts between investors and banks, when a bank run happens only the early withdrawers can get promised $d_{0}^{i}$ with the bank's run value; for the liquidity contracts between banks and entrepreneurs at $t=1$, although in equilibrium the contracted interest rate is bid up by the competing banks to the level that the entrepreneurs seize all the return from the risky projects in the good state of the world at $t=2$ (the details will be explained later), the entrepreneurs cannot claim more than the actual yields in the bad state.



Fig. 1. The timing of the game

Here the risky project has the following special features, as shown in Fig. 1

(1) With probability $p$ the project returns early. For projects with early returns

(a) With probability $\eta$ the return is as high as $R_{2}$;

(b) With probability $1-\eta$ the return is as low as 0 ;

(2) With probability $1-p$ the project returns late. For projects with late 
returns

(a) With probability $\eta$ the return is as high as $R_{2}$;

(b) With probability $1-\eta$ the return is as low as 0 .

$p$ can take three values, $p_{L}<\bar{p}<p_{H}$. $\eta$ can take three values as well, $\eta_{L}<\bar{\eta}<\eta_{H}$. Assume that $\eta R_{2}>R_{1}$ such that the expected return for each unit of risky asset invested at $t=0$ is higher than the that for safe asset.

At $t=\frac{1}{2}, p \cdot \eta$, or the early return from the risky projects, becomes public information. However, no player, even the bank managers themselves, knows the exact values of $p$ and $\eta$. Further, assume that there can be only one shock at $t=1$, i.e. it's only possible that either $p$ or $\eta$ takes its "extreme" value, but not both. For simplicity, assume there are only two possible values for $p \cdot \eta$ and $(p \cdot \eta)_{L}=\bar{p} \cdot \eta_{L}=\bar{\eta} \cdot p_{L}<\bar{p} \cdot \eta_{H}=\bar{\eta} \cdot p_{H}=(p \cdot \eta)_{H}$. The higher early return, $(p \cdot \eta)_{H}$, occurs with probability $\pi$ and the lower early return, $(p \cdot \eta)_{L}$, occurs with probability $1-\pi$. Therefore,

(1) If one observes a high $p \cdot \eta$, it may comes from either $p_{H}$ (with probability $\sigma)$ or $\eta_{H}$ (with probability $\left.1-\sigma\right)$;

(2) If one observes a low $p \cdot \eta$, it may comes from either $p_{L}$ (with probability $\sigma)$ or $\eta_{L}$ (with probability $1-\sigma$ ).

Such $p-\eta$ setting captures the dual concerns in banking industry. $p$ defines how likely the cash flow is materialized earlier, i.e. the liquidity of the risky projects, and $\eta$ defines how successful the projects are - or, how likely the banks stay solvent.

In the following, we first analyze the baseline case in which there's no uncertainty concerning the values of $p$ and $\eta$. Then the model is extended to the case in which the true reason for a liquidity shock is not discernable. 


\subsection{The baseline result (when $p$ and $\eta$ are deterministic)}

Suppose that both $p$ and $\eta$ are deterministic. In this case, the expected return for each unit of risky asset invested at $t=0$ is

$$
\mathbb{E}\left[R_{2}\right]=p \eta R_{2}+(1-p) \eta R_{2}=\eta R_{2}
$$

Then for each unit deposit the bank manager collects, her liability to her depositors is

$$
\alpha \gamma R_{1}+(1-\alpha) \gamma \mathbb{E}\left[R_{2}\right]=\alpha \gamma R_{1}+(1-\alpha) \gamma \eta R_{2}
$$

and at $t=1$ the aggregate liquidity available is

$$
\alpha R_{1}+(1-\alpha) p \eta R_{2}
$$

The optimal symmetric equilibrium is therefore given by the $\alpha$ that equates these two terms, i.e.

$$
\alpha \gamma R_{1}+(1-\alpha) \gamma \eta R_{2}=\alpha R_{1}+(1-\alpha) p \eta R_{2}
$$

Solving, we obtain

$$
\alpha=\frac{\gamma-p}{(\gamma-p)+(1-\gamma) \frac{R_{1}}{\eta R_{2}}}=\frac{1}{1+(1-\gamma) \frac{R_{1}}{\eta R_{2}(\gamma-p)}}
$$

When $\eta=1$, i.e. no insolvency risk, equation (1) degenerates to the baseline case in Cao \& Illing (2008). It can be seen that $\frac{\partial \alpha}{\partial \eta}>0$, i.e. when insolvency is less severe, illiquidity problem dominates so that more funds should be invested on the safe assets; similarly, since $\frac{\partial \alpha}{\partial p}<0$, more funds should be invested on the safe assets when the long term projects get riskier. 


\subsection{Introducing aggregate risk (when $p$ and $\eta$ are stochastic)}

Now suppose that at $t=\frac{1}{2}$, the value $p \cdot \eta$ is stochastic, i.e. either $(p \cdot \eta)_{H}$ or $(p \cdot \eta)_{L}$ is observed. Then $(p \cdot \eta)_{H}$ reveals

- If the true state is $p_{H}$ with $\bar{\eta}$, then the expected return from the late risky projects at $t=2$ is $\left(1-p_{H}\right) \bar{\eta} R_{2}$;

- If the true state is $\eta_{H}$ with $\bar{p}$, then the expected return from the late risky projects at $t=2$ is $(1-\bar{p}) \eta_{H} R_{2}$.

So the expected return at $t=2$ is given by

$$
\begin{aligned}
R_{2}^{H} & =\left[\left(1-p_{H}\right) \bar{\eta} \sigma+(1-\bar{p}) \eta_{H}(1-\sigma)\right] R_{2} \\
& =\left[\bar{\eta} \sigma+(1-\bar{p}-\sigma) \eta_{H}\right] R_{2} \\
& =[(1-\bar{p}) \bar{\eta}+(1-\bar{p}-\sigma) \underbrace{\left(\eta_{H}-\bar{\eta}\right)}_{>0}] R_{2}
\end{aligned}
$$

and the aggregate expected return from the risky projects is

$$
\mathbb{E}\left[R_{2} \mid(p \cdot \eta)_{H}\right]=(p \cdot \eta)_{H} R_{2}+\left[(1-\bar{p}) \bar{\eta}+(1-\bar{p}-\sigma)\left(\eta_{H}-\bar{\eta}\right)\right] R_{2}
$$

Similarly when $(p \cdot \eta)_{L}$ is observed at $t=\frac{1}{2}$, then

- If the true state is $p_{L}$ with $\bar{\eta}$, then the expected return from the late risky projects at $t=2$ is $\left(1-p_{L}\right) \bar{\eta} R_{2}$;

- If the true state is $\eta_{L}$ with $\bar{p}$, then the expected return from the late risky projects at $t=2$ is $(1-\bar{p}) \eta_{L} R_{2}$.

So the expected return from the late risky projects at $t=2$ is given by

$$
\begin{aligned}
R_{2}^{L} & =\left[\left(1-p_{L}\right) \bar{\eta} \sigma+(1-\bar{p}) \eta_{L}(1-\sigma)\right] R_{2} \\
& =\left[\bar{\eta} \sigma+(1-\bar{p}-\sigma) \eta_{L}\right] R_{2} \\
& =[(1-\bar{p}) \bar{\eta}+(1-\bar{p}-\sigma) \underbrace{\left(\eta_{L}-\bar{\eta}\right)}_{<0}] R_{2},
\end{aligned}
$$


and the aggregate expected return from the risky projects is

$$
\mathbb{E}\left[R_{2} \mid(p \cdot \eta)_{L}\right]=(p \cdot \eta)_{L} R_{2}+\left[(1-\bar{p}) \bar{\eta}+(1-\bar{p}-\sigma)\left(\eta_{L}-\bar{\eta}\right)\right] R_{2}
$$

To make our analysis interesting, assume that

$$
\begin{aligned}
\mathbb{E}\left[R_{2} \mid(p \cdot \eta)_{H}\right] & >\mathbb{E}\left[R_{2} \mid(p \cdot \eta)_{L}\right], \\
(p \cdot \eta)_{H}-(p \cdot \eta)_{L} & >(1-\bar{p}-\sigma)\left(\eta_{L}-\eta_{H}\right) .
\end{aligned}
$$

If there's only illiquidity risk as in Cao \& Illing (2008, 2009a), the expected return from the late risky projects is just $R_{2}$ (the only thing that matters is the timing of cash flow). Now with co-existence of insolvency risk, such return is determined by the probability and scale of insolvency, as (2) and (4) suggest:

(1) In good time, the confidence in the risky assets (less likely to be insolvent) raises future expected return (hence asset price at $t=1$ );

(2) In bad time, the lack of confidence in the risky assets (more likely to be insolvent) depresses future expected return (hence asset price at $t=1$ ).

\subsection{Equilibria for the laissez-faire economy}

Suppose that $(p \cdot \eta)_{H}$ is the only intermediate state of the world and all the bank managers set their $\alpha$, call it $\alpha_{H}$, according to that. Then the equilibrium should be the $\alpha_{H}$ under which the banks get the cheapest liquidity without bank runs, i.e.

$$
\begin{aligned}
\alpha_{H} \gamma R_{1}+\left(1-\alpha_{H}\right) \gamma \mathbb{E}\left[R_{2} \mid(p \cdot \eta)_{H}\right] & =\gamma \underbrace{\left\{\alpha_{H} R_{1}+\left(1-\alpha_{H}\right) \mathbb{E}\left[R_{2} \mid(p \cdot \eta)_{H}\right]\right\}}_{\mathbb{E}\left[R_{H}\right]} \\
& =\alpha_{H} R_{1}+\left(1-\alpha_{H}\right)(p \cdot \eta)_{H} R_{2} \\
\alpha_{H} & =\frac{1}{1+(1-\gamma) \frac{R_{1}}{\gamma \mathbb{E}\left[R_{2} \mid(p \cdot \eta)_{H}\right]-(p \cdot \eta)_{H} R_{2}}} .
\end{aligned}
$$


Similar as in Cao \& Illing (2008), assume that $\gamma \mathbb{E}\left[R_{2} \mid(p \cdot \eta)_{H}\right]>(p \cdot \eta)_{H} R_{2}$ to ensure that banks need to hold both liquid and illiquid assets.

If $(p \cdot \eta)_{L}$ is the only intermediate state of the world and all the bank managers set their $\alpha$, call it $\alpha_{L}$, according to that, then

$$
\alpha_{L}=\frac{1}{1+(1-\gamma) \frac{R_{1}}{\gamma \mathbb{E}\left[R_{2} \mid(p \cdot \eta)_{L}\right]-(p \cdot \eta)_{L} R_{2}}} .
$$

Similar as before, assume that $\gamma \mathbb{E}\left[R_{2} \mid(p \cdot \eta)_{L}\right]>(p \cdot \eta)_{L} R_{2}$.

To simplify the notation in the following, denote

$$
\mathbb{E}\left[R_{H}\right]=\alpha_{H} R_{1}+\left(1-\alpha_{H}\right) \mathbb{E}\left[R_{2} \mid(p \cdot \eta)_{H}\right]
$$

as well as

$$
\mathbb{E}\left[R_{L}\right]=\alpha_{L} R_{1}+\left(1-\alpha_{L}\right) \mathbb{E}\left[R_{2} \mid(p \cdot \eta)_{L}\right]
$$

The equilibria for the laissez-faire economy are then summarized in the following proposition:

Proposition 2.1 The equilibria for the laissez-faire economy depend on the value of $\pi$, such that

(1) There is a unique optimal symmetric equilibrium in pure strategies such that all the banks set $\alpha^{*}=\alpha_{H}$ as long as the probability of $(p \cdot \eta)_{H}$ satisfies $\pi>\bar{\pi}_{2}=\frac{\gamma \mathbb{E}\left[R_{L}\right]-c}{\gamma \mathbb{E}\left[R_{H}\right]-c}$. In addition,

(a) At $t=0$ the banks offer the investors a deposit contract with $d_{0}=\gamma \mathbb{E}\left[R_{H}\right]$;

(b) The banks survive at $(p \cdot \eta)_{H}$, but experience a run at $(p \cdot \eta)_{L}$;

(c) The investors' expected return is $\mathbb{E}\left[R\left(\alpha_{H}, c\right)\right]=\pi d_{0}+(1-\pi) c$;

(2) There exists a unique optimal symmetric equilibrium in pure strategies such that all the banks set $\alpha^{*}=\alpha_{L}$ as long as the probability of $(p \cdot \eta)_{H}$ satisfies $0 \leq \pi<\bar{\pi}_{1}=\frac{\gamma \mathbb{E}\left[R_{L}\right]-c}{\gamma \mathbb{E}\left[R_{2} \mid(p \cdot \eta)_{L}\right]-c}$. In addition,

(a) At $t=0$ the banks offer the investors a deposit contract with $d_{0}=\gamma \mathbb{E}\left[R_{L}\right]$;

(b) The banks survive at both $(p \cdot \eta)_{H}$ and $(p \cdot \eta)_{L}$; 
(c) The investors' expected return is $\mathbb{E}\left[R\left(\alpha_{L}\right)\right]=d_{0}$;

(d) At $(p \cdot \eta)_{H}$ the bank managers get a rent of $\gamma\left(1-\alpha_{L}\right)\left(\mathbb{E}\left[R_{2} \mid(p \cdot \eta)_{H}\right]-\mathbb{E}\left[R_{2} \mid(p \cdot \eta)_{L}\right]\right)$ for each unit of deposit;

(3) When $\pi \in\left[\bar{\pi}_{1}, \bar{\pi}_{2}\right]$ there exists no symmetric equilibrium in pure strategies. What's more, there exists a unique mixed strategy equilibrium in which for a representative bank manager

(a) With probability $\theta$ the bank chooses to be a free-rider - those who set $\alpha_{r}^{*}=0$, offer high return for investors at $(p \cdot \eta)_{H}$ and are run at $(p \cdot \eta)_{L}$; and with probability $1-\theta$ to be prudent - those who set $\alpha_{s}^{*}>0$ and survive both $(p \cdot \eta)_{H}$ and $(p \cdot \eta)_{L}$;

(b) At $t=0$ a naughty bank offers a deposit contract with higher return $d_{0}^{r}=\gamma\left[(p \cdot \eta)_{H} R_{2}+\frac{R_{2}^{H}}{r_{H}}\right]$, but the banks is run when $(p \cdot \eta)_{L}$ is observed; a prudent bank offers a deposit contract with lower return $d_{0}^{s}=\gamma\left[\alpha_{s}^{*} R_{1}+\left(1-\alpha_{s}^{*}\right)(p \cdot \eta)_{H} R_{2}+\frac{\left(1-\alpha_{s}^{*}\right) R_{2}^{H}}{r_{H}}\right]$, but the banks survive in both states;

(c) The expected returns for both types are equal, i.e. $\pi d_{0}^{r}+(1-\pi) c=d_{0}^{s}$, and the probability $\theta$ is determined by market clearing condition, which equates liquidity supply and demand in both states;

(d) The expected returns for prudent banks are equal at both states. Especially, at $(p \cdot \eta)_{L}$

$$
\begin{aligned}
d_{0}^{s}= & \min \left\{\alpha_{s}^{*} R_{1}+\left(1-\alpha_{s}^{*}\right)(p \cdot \eta)_{L} R_{2}, \gamma\left[\alpha_{s}^{*} R_{1}+\left(1-\alpha_{s}^{*}\right)(p \cdot \eta)_{L} R_{2}\right.\right. \\
& \left.\left.+\left(1-\alpha_{s}^{*}\right) R_{2}^{L}\right]\right\} .
\end{aligned}
$$

Moreover, $r_{L}=1$ with $\alpha_{s}^{*} \geq \alpha_{L}$ when

$$
d_{0}^{s}=\gamma\left[\alpha_{s}^{*} R_{1}+\left(1-\alpha_{s}^{*}\right)(p \cdot \eta)_{L} R_{2}+\left(1-\alpha_{s}^{*}\right) R_{2}^{L}\right]
$$

and $r_{L} \geq 1$ with $\alpha_{s}^{*} \leq \alpha_{L}$ when

$$
d_{0}^{s}=\alpha_{s}^{*} R_{1}+\left(1-\alpha_{s}^{*}\right)(p \cdot \eta)_{L} R_{2} .
$$

$\alpha_{s}^{*}=\alpha_{L}$ only when

$$
\begin{aligned}
& \gamma\left[\alpha_{s}^{*} R_{1}+\left(1-\alpha_{s}^{*}\right)(p \cdot \eta)_{L} R_{2}+\left(1-\alpha_{s}^{*}\right) R_{2}^{L}\right] \\
= & \alpha_{s}^{*} R_{1}+\left(1-\alpha_{s}^{*}\right)(p \cdot \eta)_{L} R_{2} .
\end{aligned}
$$




\section{Proof See Appendix A.1.}

So far the results seem to be similar as those in Cao \& Illing (2008). Although the ambiguity between illiquidity and insolvency problems makes four states of the world at $t=2$, namely $\left(p_{H}, \bar{\eta}\right),\left(\eta_{H}, \bar{p}\right),\left(p_{L}, \bar{\eta}\right)$, and $\left(\eta_{L}, \bar{p}\right)$, only two signals are actually observed in $t=1$. As long as the equilibria are still driven by just two $t=1$ signals, the outcomes should be of similar pattern.

The difference here lies in the mixed strategy equilibrium, i.e. what PropoSITION 2.1 (3d) shows. Recall that in the presence of pure illiquidity risks, the expected return of the risky assets remains the same (i.e. $R_{2}$ ) in both states because the only problem there is the timing of getting the fractions of the yields. But if there are additional insolvency risks as in current settings, the expected return of the risky assets differs in both states, i.e. $\mathbb{E}\left[R_{2} \mid(p \cdot \eta)_{L}\right]<\mathbb{E}\left[R_{2} \mid(p \cdot \eta)_{H}\right]$ as shown in equations (3) and (5). Therefore at $(p \cdot \eta)_{H}$ there's a trade-off for prudent banks now:

(1) $(p \cdot \eta)_{H}$ implies a lower probability of insolvency at $t=2$, therefore the value of risky assets gets higher. With higher net worth of illiquid assets, the banks are able to pledge more liquidity in liquidity market (hence, offer higher $d_{0}^{s}$ at $\left.t=0\right)$. Such "income effect" encourages prudent banks to set higher $\alpha_{s}^{*}$;

(2) $(p \cdot \eta)_{H}$ implies higher early return from the risky projects, making it easier to fulfill $d_{0}^{s}$. Such "substitution effect" discourages prudent banks to set higher $\alpha_{s}^{*}$.

The equilibrium value $\alpha_{s}^{*}$ then depends on the cost of the banks' liquidity financing at $t=1$, i.e. the interest rate $r_{H}$. Since $r_{H}$ is bid up by the free-riders, or the naughty banks, its value reflects the incentive for free-riding, which hinges on the probability of being in a good state, $\pi$

(1) When $\pi$ is just a bit higher than $\bar{\pi}_{1}$, the profitability of free-riding is not much higher than being prudent. Therefore, there won't be many free- 
riders and $r_{H}$ won't be that high. The prudent banks can thus pledge more liquidity with their risky assets, i.e. they can get higher early return while they need less high yield risky assets to fulfill $d_{0}^{s}$. In this case "substitution effect" dominates and prudent banks will choose to set a higher $\alpha_{s}^{*}$;

(2) When $\pi$ is much higher than $\bar{\pi}_{1}$, the profitability of free-riding is much higher than being prudent. Therefore, there will be many free-riders and $r_{H}$ will be high. The prudent banks thus cannot pledge more liquidity with their risky assets, i.e. they have to fulfill $d_{0}^{s}$ by competing for liquidity. In this case "income effect" dominates and prudent banks will choose to set a lower $\alpha_{s}^{*}$.

The investors' expected return in equilibrium as a function of $\pi$ is summarized in Fig. 2.

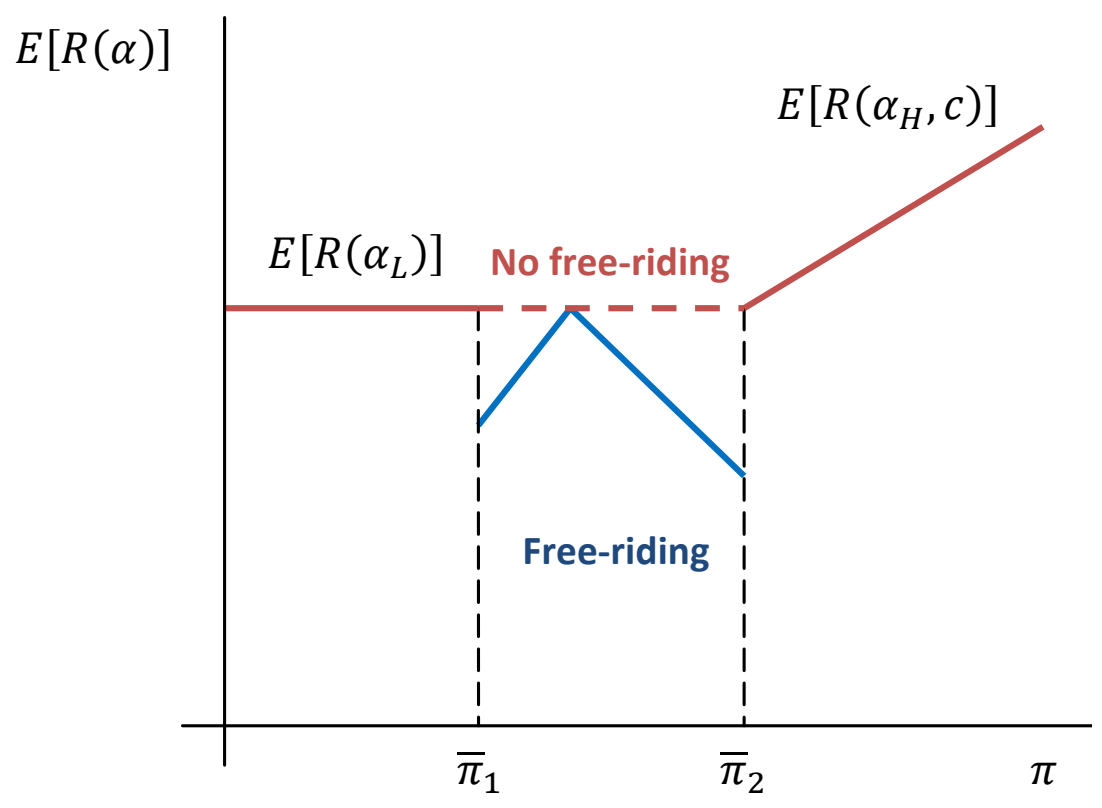

Fig. 2. Investors' expected return in laissez-faire economy

To summarize, when the liquidity and insolvency problem coexist, the inefficiencies arise from: (1) the inferior mixed strategy equilibrium - the investors' expected return is lower whenever $\alpha_{s}^{*} \neq \alpha_{L}, \forall \pi \in\left[\bar{\pi}_{1}, \bar{\pi}_{2}\right]$ and (2) the costly bank runs. However, as the next section shows, when it comes to 
banking regulation, typical (one-handed) schemes may be no longer optimal and may even become infeasible when insolvency is present.

\section{Liquidity regulation, nominal contract and Lender of Last Resort pol- icy}

We now introduce a central bank as a fourth player. Banks are required to invest a minimum level $\underline{\alpha}$ on safe projects, and only those who observe the rules of the game will be offered the lifeboat when there's liquidity shortage. Liquidity injection is implemented via creating fiat money, and the timing of the game is summarized as Fig. 3. The key elements in this section are as following:

Nominal contracts Since central banks don't produce real goods, rather, they increase liquidity supply by printing fiat money at zero cost, therefore in this section all financial contracts have to be nominal, i.e. one unit of money is of equal value to one unit real good in payment and central bank's liquidity injection inflates the nominal price by cash-in-the-market principle à la Allen \& Gale (2004) — the nominal price is equal to the ratio of amount of liquidity (the sum of money and real goods) in the market to amount of real goods;

Liquidity regulation At $t=0$ a minimum level $\underline{\alpha}$ of investment on safe projects is announced by the central bank;

Conditional entry and bailout In the following, liquidity requirement $\underline{\alpha}$ is both a requirement for entry to the banking industry and a prerequisite for receiving liquidity injection.

\subsection{Liquidity regulation with conditional bailout}

Recall that, in the presence of pure illiquidity risk, liquidity injection eliminates the costly bank run, reducing inefficiency, as Cao \& Illing (2009a) 


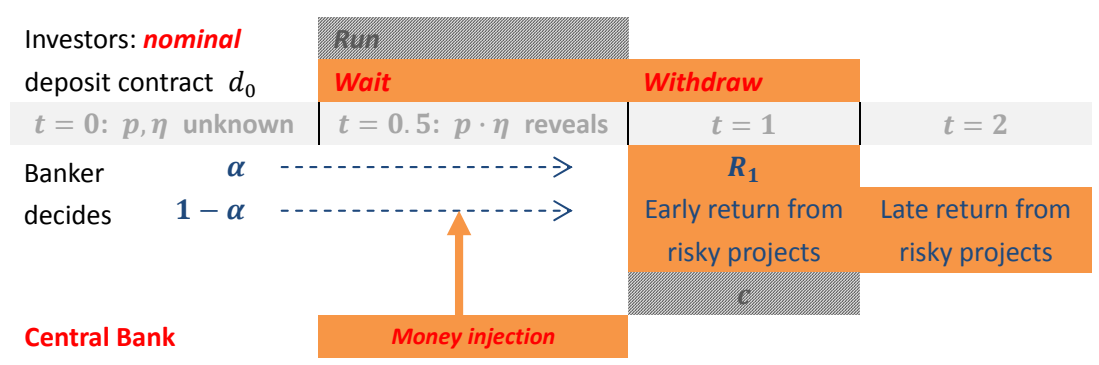

Fig. 3. The timing of the game with central bank

suggests. Suppose the same policy is applied: at $t=0$ all banks are required to invest $\underline{\alpha}=\alpha_{H}$ when $\pi>\bar{\pi}_{2}$, and will be bailed out by the liquidity injected against their assets as collateral when necessary. Then when $(p \cdot \eta)_{H}$ is indeed observed, the banks can meet the depositors' demand without the need for liquidity injection, i.e.

$$
d_{0}=\alpha_{H} \gamma R_{1}+\left(1-\alpha_{H}\right) \gamma \mathbb{E}\left[R_{2} \mid(p \cdot \eta)_{H}\right]
$$

However, when $(p \cdot \eta)_{L}$ is observed, the nominal contract on $d_{0}$ cannot be met purely by the banks' expected real return so that they need to apply for central bank's liquidity injection using their assets as collateral. However, since there's a positive probability that the banks may be insolvent, the central bank can only inject liquidity up to the fair value of the the risky projects, i.e. the expected return of the risky assets, or, in this case, the maximum nominal payoff the depositors can get

$$
\begin{aligned}
\left.d_{0}\right|_{(p \cdot \eta)_{L}} & =\alpha_{H} \gamma R_{1}+\left(1-\alpha_{H}\right) \gamma \mathbb{E}\left[R_{2} \mid(p \cdot \eta)_{L}\right] \\
& <d_{0}
\end{aligned}
$$

— the banks will still be run even if they obtain the promised lifeboat from the central bank, and the outcome is no different from that in the laissez-faire economy. The scheme fails to eliminate the inefficient bank runs for $\pi>\bar{\pi}_{2}$, and the outcome is the same as that in the laissez-faire economy.

For $0 \leq \pi \leq \bar{\pi}_{2}$, the liquidity requirement should be $\underline{\alpha}=\alpha_{L}$. Since $\underline{\alpha}$ is also the entry requirement for the entire banking industry, it is no longer 
possible to free-ride for intermediate values of $\pi$; the inferior mixed strategy equilibrium is thus eliminated, which improves efficiency. On the other hand, banks survive on both contingencies by setting $\underline{\alpha}=\alpha_{L}$, so there will be no need for liquidity injection.

With both illiquidity and insolvency risk, this scheme can only eliminate the inefficiency from the mixed strategy equilibrium (by imposing liquidity requirement $\underline{\alpha}=\alpha_{L}$ for $0 \leq \pi \leq \bar{\pi}_{2}$ ), but fails to avoid the high cost from bank runs. In this case, it's effectiveness is rather limited.

\subsection{Conditional liquidity injection with procyclical taxation}

The failure of this scheme comes from the following fact: the insolvency risk brings a wedge between the expected return of the late risky projects at $(p \cdot \eta)_{H}$ and that at $(p \cdot \eta)_{L}$; therefore, even if the banks are guaranteed a liquidity injection when time is bad, they are not able to obtain as much liquidity as they need - in other words, the potential insolvency risk adds an extra cost to stabilizing the financial system. This suggests that the regulator needs to find a second instrument for covering such cost, for example, an additional procyclical taxation may help solve this problem by imposing a tax at $t=0$ on the banks' revenue when $(p \cdot \eta)_{H}$ is observed, and bailing out the troubled banks with liquidity injection plus such a tax revenue when $(p \cdot \eta)_{L}$ is observed.

The proposed augmented scheme works as follows. At $t=0$, a minimum liquidity requirement, the minimum share $\underline{\alpha}_{T}$ of the funds invested on the safe projects, is imposed on all banks and at $t=1$ the banks are taxed away a certain amount $T_{H} \geq 0$ out of their revenue when $(p \cdot \eta)_{H}$ is observed. The banks are bailed out with liquidity injection (with their assets as collateral) plus the tax revenue when $(p \cdot \eta)_{L}$ is observed - surely in this case the banks pay no tax, $T_{L}=0$.

$\underline{\alpha}_{T}$ and $T_{H}$ are determined by $\pi$, i.e. regulatory policies are only introduced 
where there are inefficiencies

(1) For $\pi \geq \bar{\pi}_{2}$, a positive tax $T_{H}>0$ is levied at $(p \cdot \eta)_{H}$ and the revenue is used as bailout funds at $(p \cdot \eta)_{H}$. Bank managers have to set $\left(\alpha_{H, T}, d_{0, T}\right)$ at $t=0$ by internalizing $T_{H}$ as an additional cost at $t=1$. In this case, costly bank run is the source of inefficiency which is to be entirely eliminated by the conditional liquidity injection and the tax;

(2) For $0 \leq \pi \leq \bar{\pi}_{1}$, banks are required to set $\underline{\alpha}_{T}=\alpha_{L}$ as an entry condition. Since the inefficient mixed strategy equilibrium is deterred by imposing such obligation, and the banks always survive in this case, no safety funds are necessary. Therefore, $T_{H}=0$.

Now we have to examine whether this scheme works; and if yes, how much $T_{H}$ should be imposed. Let's concentrate on the case where $T_{H}>0$, i.e. $\pi \geq \bar{\pi}_{2} \cdot\left(\alpha_{H, T}, d_{0, T}\right)$ is set by

$$
\begin{aligned}
\alpha_{H, T} \gamma R_{1}+\left(1-\alpha_{H, T}\right) \gamma \mathbb{E}\left[R_{2} \mid(p \cdot \eta)_{H}\right]-T_{H} & =\alpha_{H, T} R_{1}+\left(1-\alpha_{H, T}\right)(p \cdot \eta)_{H} R_{2} \\
& =d_{0, T}
\end{aligned}
$$

The liquidity requirement $\underline{\alpha}_{T}$ should be so high that the banks are just able to utilize the resources optimally (as equation (7) shows), i.e. $\underline{\alpha}_{T}=\alpha_{H, T}$, and the conditional bailout policy must make sure that the banks are not to be run in the worst case, i.e.

$$
\begin{aligned}
& \alpha_{H, T} \gamma R_{1}+\left(1-\alpha_{H, T}\right) \gamma \mathbb{E}\left[R_{2} \mid(p \cdot \eta)_{H}\right]-T_{H} \\
= & \alpha_{H, T} \gamma R_{1}+\left(1-\alpha_{H, T}\right) \gamma \mathbb{E}\left[R_{2} \mid(p \cdot \eta)_{L}\right]+T_{H} \frac{\pi}{1-\pi}
\end{aligned}
$$

$\alpha_{H, T}, d_{0, T}$, and $T_{H}$ are determined by solving equations (7) and (8)

$$
\left\{\begin{array}{l}
\alpha_{H, T}=\frac{(p \cdot \eta)_{H} R_{2}-\gamma \pi \mathbb{E}\left[R_{2} \mid(p \cdot \eta)_{H}\right]+\gamma \pi \mathbb{E}\left[R_{2} \mid(p \cdot \eta)_{L}\right]-\gamma \mathbb{E}\left[R_{2} \mid(p \cdot \eta)_{L}\right]}{\gamma R_{1}-R_{1}+(p \cdot \eta)_{H} R_{2}-\gamma \pi \mathbb{E}\left[R_{2} \mid(p \cdot \eta)_{H}\right]-\gamma \mathbb{E}\left[R_{2} \mid(p \cdot \eta)_{L}\right]+\gamma \pi \mathbb{E}\left[R_{2} \mid(p \cdot \eta)_{L}\right]}, \\
d_{0, T}=-\frac{\gamma R_{1}\left\{\pi\left(\mathbb{E}\left[R_{2} \mid(p \cdot \eta)_{H}\right]-\mathbb{E}\left[R_{2} \mid(p \cdot \eta)_{L}\right]\right)+\mathbb{E}\left[R_{2} \mid(p \cdot \eta)_{L}\right]-(p \cdot \eta)_{H} R_{2}\right\}}{\gamma R_{1}-R_{1}+(p \cdot \eta)_{H} R_{2}-\gamma \pi \mathbb{E}\left[R_{2} \mid(p \cdot \eta)_{H}\right]-\gamma \mathbb{E}\left[R_{2} \mid(p \cdot \eta)_{L}\right]+\gamma \pi \mathbb{E}\left[R_{2} \mid(p \cdot \eta)_{L}\right]^{\prime}} \\
T_{H}=\frac{\gamma R_{1}(\pi-1)(1-\gamma)\left(\mathbb{E}\left[R_{2} \mid(p \cdot \eta)_{H}\right]-\mathbb{E}\left[R_{2} \mid(p \cdot \eta)_{L}\right]\right)}{\gamma R_{1}-R_{1}+(p \cdot \eta)_{H} R_{2}-\gamma \pi \mathbb{E}\left[R_{2} \mid(p \cdot \eta)_{H}\right]-\gamma \mathbb{E}\left[R_{2} \mid(p \cdot \eta)_{L}\right]+\gamma \pi \mathbb{E}\left[R_{2} \mid(p \cdot \eta)_{L}\right]}
\end{array}\right.
$$


To get rid of complications, further assume that $\gamma \mathbb{E}\left[R_{2} \mid(p \cdot \eta)_{L}\right]>(p \cdot \eta)_{H} R_{2}$, i.e. even in the worst case, it is still appealing for the banks to hold both liquid and illiquid assets.

The effectiveness of the scheme is summarized in the following proposition:

Proposition 3.1 When $\pi \geq \bar{\pi}_{2}$, with $\underline{\alpha}_{T}$ as both the requirement for entry to the banking industry and a prerequisite for getting liquidity injection from the central bank, as well as an additional tax $T_{H}$ charged at $(p \cdot \eta)_{H}$ as safety funds for rescuing banks at $(p \cdot \eta)_{H}$, the required $\underline{\alpha}_{T}$ should be so high that $\underline{\alpha}_{T}>\alpha_{H}$ and the corresponding investors' expected return is (weakly) higher than that in the laissez-faire economy under the same $\pi$, as long as $c$ is sufficiently small.

Proof See Appendix A.2.

The intuition behind the proposition is fairly straightforward. The gain from such modified scheme is to avoid the costly bank runs, however, the scheme also adds additional direct and indirect costs for banking business. The direct one comes from $T_{H}$, the "safety funds" to make up the losses in bad time as equation (8) shows, i.e. to distribute the tax revenue in the downturn, $T_{H} \frac{\pi}{1-\pi}$; the indirect one comes from $\alpha_{H, T}-$ at $t=0$ the banks have to invest more on the safe projects to pay the tax at $t=1$, leaving less resources for risky, but high yield projects. When $\pi$ is sufficiently high and the bad state seldom happens, the regulator doesn't need to charge too high $T_{H}$ and the regulatory cost is comparatively lower than the economy's gain from the regulation, and this is more likely to hold when the gain from avoiding bank runs (i.e. when $c$ is sufficiently small) is sufficiently large.

Fig. B.1 (APPEndix B) visualizes the results by numerical simulation. When the cost of bank runs is fairly high (too low $c$ ), this scheme significantly improves efficiency when $\pi$ is high, where $T_{H}$ doesn't need to be high and the opportunity cost from investing on higher $\alpha_{H, T}$ is much lower than the gain from completely avoiding bank runs.

However, in reality such safety funds via procyclical taxation are certainly 
subject to implementation difficulties. The funds have to be accumulated to a sufficient amount before they are in need, i.e. when a crisis hits. Otherwise, when a crisis comes before the funds are fully established, the government must face a public deficit which can only be covered by the future taxation revenue. Usually raising public deficits implies political debates and compromises, substantially restricting the effectiveness of such scheme. In this sense, a "self-sufficient" solution such as equity holding may be superior, which is to be studied in the next section.

\section{Insolvency risk and equity requirement}

As seen above, with the coexistence of both illiquidity and insolvency risks, the scheme of liquidity requirement with conditional bailout only works if an additional cost is introduced. Such cost can be either "external", for example, establishing safety funds via taxation as the past section suggested, or "internal", for example, covering the cost with equity holdings. In current settings, introducing equity requirement may not be as costly as in Cao \& Illing (2009a) since the cheaper stabilizing instrument there ceases to work here. Therefore, compared with the bigger cost caused by bank runs, imposing a costly equity requirement may be the lesser of two evils.

\subsection{Pure equity requirement and narrow banking}

Now suppose an equity requirement is adopted as a sole instrument for the regulator to stabilize financial system in a self-sufficient way, i.e. all the losses will be absorbed by equity holders. Here equity is introduced à la Diamond \& Rajan (2005) such that the banks issue a mixture of deposit contract and equity for the investors. Assume that the equity holders (investors) and

the bank managers share the profit equally (that is, to set $\zeta$ in Cao \& Illing (2009a) to be 0.5), i.e. in the good time the level of equity $k$ is 


$$
k=\frac{\frac{\gamma \mathbb{E}\left[R_{H}\right]-d_{0, E}}{2}}{\frac{\gamma \mathbb{E}\left[R_{H}\right]-d_{0, E}}{2}+d_{0, E}}, d_{0, E}=\frac{1-k}{1+k} \gamma \mathbb{E}\left[R_{H}\right] .
$$

The minimum equity requirement $k$ should make the banks just able to survive from bank runs in the worst contingency, i.e. all the equity is wiped out when $(p \cdot \eta)_{L}$ is observed,

$$
\frac{1-k}{1+k} \gamma \mathbb{E}\left[R_{H}\right]=\underbrace{\alpha_{H} R_{1}+\left(1-\alpha_{H}\right)(p \cdot \eta)_{L} R_{2}}_{\mathbb{E}\left[R_{H} \mid(p \cdot \eta)_{L}\right]}=d_{0, E},
$$

or,

$$
k=\frac{\gamma \mathbb{E}\left[R_{H}\right]-d_{0, E}}{\gamma \mathbb{E}\left[R_{H}\right]+d_{0, E}} .
$$

Since $\frac{\partial k}{\partial(p \cdot \eta)_{L}}<0$ by equation (9), banks need higher equity ratio to survive in the worst contingency when both (or either) of the two plagues get(s) more severe, implying a higher regulatory cost.

Fig. B.2 (Appendix B) visualizes the results by numerical simulation. Again, as Cao \& Illing (2009a) shows, holding equity is costly when $\pi$ is high (i.e. less funds are available for the risky assets with relatively safe, high yields, although costly bank runs are completely eliminated). Holding equity may be superior to the mixed strategy equilibrium of a laissez-faire economy depending on parameter values, but is inferior to conditional liquidity injection with procyclical taxation - because taxation revenue is entirely returned to investors as bailout funds, while in the current scheme part of the profits goes to bank managers as dividends. However, concerning the implementation difficulties of imposing an extra tax, this may be a necessary cost for both investors and regulators. 


\subsection{Combining equity requirement with liquidity regulation}

Liquidity requirements with conditional liquidity injections work best with pure illiquidity risk, but the scheme fails when there's additional insolvency risk. On the other hand, pure equity requirements are able to stabilize the system under both settings at a relatively high cost. Now the question is: is it possible to design a regulatory scheme that combines the advantages of these two at a minimum cost?

The answer is yes. Consider the right hand side of equation (9). If the banks are required to maintain the financial stability in a self-sufficient way, in all contingencies the depositors can only receive the same expected return as in the worst case, i.e. the total $t=1$ liquidity when time is bad. However, since there's a positive probability that the risky assets are simply illiquid, the expected future return from the risky assets can be higher, i.e. the "fair" value of the risky assets (as the right hand side of equation (6) shows) is higher. Therefore, liquidity injection from the central bank enables the banks to pledge for bailout funds up to the fair value of their late risky assets. However, as we argued in Section 3.1, 3.2, without imposing extra costs such as taxation these bailout funds won't be enough for the banks to avoid the costly bank runs, as long as there's still a positive probability that the banks will be insolvent. The regulator can impose equity requirement to cover this part of the cost. By doing so, since the banks need equity to cover only part of the regulatory cost, it'll be much less costly for the banks to carry equity.

The proposed regulatory scheme is as follows. First, all the banks are required to invest $\underline{\alpha}_{E}=\alpha_{H}$ of their funds on safe assets at $t=0$ for high $\pi$, and $\underline{\alpha}_{E}=\alpha_{L}$ for low $\pi$ (the cutoff value of $\pi$ is different from $\bar{\pi}_{2}$, and we'll compute it later); second, all the banks are required to meet a minimum equity ratio $k^{\prime}$ for high $\pi^{1}$. The banks are bailed out by liquidity injection in

$\overline{1}$ For sufficiently low $\pi$ the banks coordinate on the safe strategy, therefore there will be no bank runs and no need for liquidity injection, hence no need for equity 
the form of fiat money provision when time is bad. In this case, the regulator only needs to set $k^{\prime}$ to fill in the gap after a liquidity injection when $(p \cdot \eta)_{L}$ is observed, i.e.

$$
\frac{1-k^{\prime}}{1+k^{\prime}} \gamma \mathbb{E}\left[R_{H}\right]=\alpha_{H} \gamma R_{1}+\left(1-\alpha_{H}\right) \gamma \mathbb{E}\left[R_{2} \mid(p \cdot \eta)_{L}\right]
$$

in which $k^{\prime}<k$ since the right hand side of (10) is higher than that of (9). Then when $(p \cdot \eta)_{H}$ is observed, the investors' real expected return is $\frac{1-k^{\prime}}{1+k^{\prime}} \gamma \mathbb{E}\left[R_{H}\right]$. However, when $(p \cdot \eta)_{L}$ is observed, the investors' real expected return is $\mathbb{E}\left[R_{H} \mid(p \cdot \eta)_{L}\right]$ (the right hand side of (9)) and the liquidity is injected for the banks to meet the nominal deposit contract. Therefore, the investors' real expected return is

$$
\begin{aligned}
& \frac{1-k^{\prime}}{1+k^{\prime}} \gamma \mathbb{E}\left[R_{H}\right] \pi+(1-\pi) \mathbb{E}\left[R_{H} \mid(p \cdot \eta)_{L}\right] \\
= & \left\{\alpha_{H} \gamma R_{1}+\left(1-\alpha_{H}\right) \gamma \mathbb{E}\left[R_{2} \mid(p \cdot \eta)_{L}\right]\right\} \pi+(1-\pi) \mathbb{E}\left[R_{H} \mid(p \cdot \eta)_{L}\right] .
\end{aligned}
$$

For sufficiently low $\pi$ the banks coordinate on the safe strategy, i.e. $\alpha^{*}=$ $\underline{\alpha}_{E}=\alpha_{L}$, and the investors' expected return is $\gamma \mathbb{E}\left[R_{L}\right]$. It pays off for the banks to choose $\alpha_{L}$ instead of $\alpha_{H}$ only if they get higher expected real return than (11), i.e. when

$$
\begin{aligned}
& \gamma \mathbb{E}\left[R_{L}\right]>\frac{1-k^{\prime}}{1+k^{\prime}} \gamma \mathbb{E}\left[R_{H}\right] \pi+(1-\pi) \mathbb{E}\left[R_{H} \mid(p \cdot \eta)_{L}\right], \\
& \gamma \mathbb{E}\left[R_{L}\right]>\left\{\alpha_{H} \gamma R_{1}+\left(1-\alpha_{H}\right) \gamma \mathbb{E}\left[R_{2} \mid(p \cdot \eta)_{L}\right]\right\} \pi+(1-\pi) \mathbb{E}\left[R_{H} \mid(p \cdot \eta)_{L}\right]
\end{aligned}
$$

The solution gives the cutoff value $\bar{\pi}_{2}^{\prime}$, which can be solved from (12) when it holds with equality

$$
\bar{\pi}_{2}^{\prime}=\frac{\gamma \mathbb{E}\left[R_{L}\right]-\mathbb{E}\left[R_{H} \mid(p \cdot \eta)_{L}\right]}{\alpha_{H} \gamma R_{1}+\left(1-\alpha_{H}\right) \gamma \mathbb{E}\left[R_{2} \mid(p \cdot \eta)_{L}\right]-\mathbb{E}\left[R_{H} \mid(p \cdot \eta)_{L}\right]} .
$$

Fig. B.3 (Appendix B) visualizes the results by numerical simulation. Such hybrid scheme indeed effectively reduces regulatory costs in comparison to cover the gap in bailout funds. 
to pure equity requirement, since the banks do not have to hold that much equity to stabilize the system, i.e. regulator needs two instruments to deal with two plagues.

Fig. B.4 (Appendix B) compares the investors' returns under all schemes. Again, the outcome under conditional liquidity injection with procyclical taxation is superior to all the others, since all the profits that are levied as the safety tax will be entirely returned to the investors. However, when the political cost is too high to impose an extra tax and raise public deficit, combining the advantages of liquidity regulation and equity requirement is the best self-sufficient scheme.

\section{Conclusion}

In the existing banking literature, illiquidity and insolvency shocks are usually insulated in the sense that market participants have perfect knowledge about the type of the shock. This paper attempts to model the new feature of modern finance that financial innovation makes it harder to tell whether a financial institution is illiquid or insolvent. Such ambiguity doesn't only alter the equilibrium outcomes under a laissez-faire economy, but also significantly complicates the regulator's roadmaps.

In order to capture the core of the problem in a relatively tractable framework, it is assumed that the only uncertainty in the economy is that market participants cannot distinguish between illiquidity and insolvency shocks. That is, when some intermediate signal, say, a negative shock if the intermediate outcome has been observed, nobody can tell whether it's because more risky projects return late (a liquidity shock) or more risky projects fail (a solvency shock). In this stage, when pricing the illiquid assets market players have to take into account the risk that the financial institution is going to be insolvent in the future. Therefore, such a price should be lower than that in an economy under pure illiquidity risks where the only problem 
is the timing of return.

Though more complicated than the prototype model, the equilibrium outcomes under a laissez-faire economy still look similar. When either of the two signals has been observed in $t=1$, there's a price of liquidity associated with it, i.e. the value of risky assets can be uniquely determined. Therefore, the banks coordinate to be safe when the probability of a bad outcome is too high, and to be risky otherwise. In the intermediate range, there's a freeriding incentive to exploit the excessive liquidity supply in the good state of the world, and the outcome here is a prevailing mixed strategy equilibrium with both prudent and naughty banks.

However, the mixed strategy equilibrium is made a bit different, compared with the prototype model in Cao \& Illing (2008), by the additional insolvency risk. A good signal doesn't only mean a higher intermediate output, but also a lower risk of future insolvency which inflates the value of illiquid assets and makes the banks able to pledge more liquidity in $t=1$, and vice versa. Therefore, the prudent banks have the trade-off between these two effects, and the balance depends on the cost of funding, which is driven by the freeriders. However, the strategic profiles of the banks in equilibrium deviate from the coordinate solution which maximizes their expected payoffs, the mixed strategy equilibrium is inferior, anyway.

Again the inefficiencies under current settings are the inferior mixed strategy equilibrium, in which the free-riding behavior makes the banks worse off than the case if the coordinate on the safe strategy, and the costly bank runs, which are to be fixed by properly designed regulatory rules. However, with the mixture of both illiquidity and insolvency risks, traditional regulatory rules need to be carefully reviewed. First, it has been shown that in th current setting, liquidity requirements with a conditional lender of last resort policy (which was the optimal scheme when there's only illiquidity risk) cease to work. The reason is fairly straightforward: when the bad state occurs, since there's a risk that the banks in trouble may be insolvent in the future, the price of the illiquidity assets is depressed. When the banks turn to 
the central bank for help, they cannot get sufficient liquidity because their collateral, i.e. their illiquid assets, are not worth as much as in the good state. Therefore, the banks will be run anyway even if they do observe the liquidity requirements!

The fact that the illiquid assets are worth less in the bad state implies that, in the presence of insolvency risk, an extra informational cost is needed for both bailing out banks ex post and making regulatory rules ex ante. One solution could be to set up a safety funds via procyclical taxation, as a complement for conditional liquidity rules. The tax revenue, which is levied in the good state, is used in the bad state to fill in the gap which is left by pure liquidity injection. Under such scheme efficiency is improved: the costly bank runs are thus entirely eliminated and the mixed strategy equilibrium is deterred by the industry's entry requirement. However, if crisis hits before the funds are fully established, a public deficit has to be initiated. Considering the political cost of increasing public deficit, it may be tricky to implement such scheme in reality.

An alternative approach to covering the informational cost is the selfsufficient way, i.e. the banking industry stabilize itself by issuing equities. The investors and bank managers share the profit in the good state, but the equity is eliminated in the bad state. As a regulatory requirement, the minimum equity level to stabilize the economy is the amount which is just sufficient to make the banks survive in the bad state. Due to the additional informational rent, more equity is required under current settings; and since holding equity is costly, the outcome is inferior to the market solution when the probability of the bad state is very low.

Now it is known that equity holding is able to cushion the financial shocks at a cost, and liquidity requirements together with conditional liquidity injection are able to partly cover the liquidity shortage in economic downturn; therefore, regulators may combine the advantages from both instruments to achieve higher efficiency. Indeed, it is shown that given that banks observe the liquidity requirement as well as the minimum equity holdings, they can 
pledge the liquidity from the central bank up to the value of their collaterals, and the rest of the cost to stay solvent is shouldered by the shareholders; and the corresponding outcome dominates the one under pure equity requirement.

However, investors achieve the highest expected return under the scheme of conditional liquidity injection with procyclical taxation because here the profit taxed away in the good state will be fully refunded in the bad state, instead of being pocketed by the bank managers under the schemes with equity holdings. But self-sufficient schemes can be implemented at a much lower political cost, which seem to be more attractive for regulators in reality. 


\section{Appendix}

\section{A Proofs}

\section{A.1 Proof of Proposition 2.1}

Proof Given that under current settings there are still two $t=1$ states of the world, the equilibria of the game can be easily constructed following the same method as in the proofs for Proposition ?? and ?? of Cao \& Illing (2008). The only necessary step here is to clarify the mixed strategy equilibrium.

When $(p \cdot \eta)_{H}$ reveals, the prudent banks get a high early return from their risky assets, i.e $(p \cdot \eta)_{H} R_{2}$. On the other hand, the value of the late assets, $R_{2}^{H}$, gets higher as well because of lower probability of insolvency and this allows them to get more liquidity in the market at $t=1$ with market rate $r_{H}$. So the trade-off for the prudent banks here is whether to invest more on liquid assets (increase $\alpha_{s}^{*}$ ) or to invest more on illiquid assets (decrease $\alpha_{s}^{*}$ ), and the reference point is $\alpha_{L}$.

The market rate $r_{H}$ is pinned down by $t=1$ liquidity demand and supply, and these are jointly determined by the number of both prudent and naughty banks (note that naughty banks only survive at $(p \cdot \eta)_{H}$ ), i.e.

(1) When $r_{H}$ is low, i.e. the free-riding incentive is not high, or $\pi$ is not high, prudent banks are able to get market liquidity at a lower cost. Therefore, there's no need to invest in more illiquid assets and it's preferable for the prudent banks to reap the early harvest, i.e. $\alpha_{s}^{*}>\alpha_{L}$ in this case. And $r_{L}=1$ because of the overinvestment in liquid assets;

(2) When $r_{H}$ is high, i.e. the free-riding incentive is high, or $\pi$ is high, prudent banks are no longer able to get market liquidity at a low cost. Therefore, they have to invest in more illiquid assets to compete with naughty banks on $t=1$ market liquidity, i.e. $\alpha_{s}^{*}<\alpha_{L}$ in this case. And 
$r_{L}>1$ because of the underinvestment in liquid assets.

\section{A.2 Proof of Proposition 3.1}

Proof To show that $\underline{\alpha}_{T}>\alpha_{H}$, we only have to show

$$
\begin{aligned}
& \frac{(p \cdot \eta)_{H} R_{2}-\gamma \pi \mathbb{E}\left[R_{2} \mid(p \cdot \eta)_{H}\right]+\gamma \pi \mathbb{E}\left[R_{2} \mid(p \cdot \eta)_{L}\right]-\gamma \mathbb{E}\left[R_{2} \mid(p \cdot \eta)_{L}\right]}{\gamma R_{1}-R_{1}+(p \cdot \eta)_{H} R_{2}-\gamma \pi \mathbb{E}\left[R_{2} \mid(p \cdot \eta)_{H}\right]-\gamma \mathbb{E}\left[R_{2} \mid(p \cdot \eta)_{L}\right]+\gamma \pi \mathbb{E}\left[R_{2} \mid(p \cdot \eta)_{L}\right]} \\
> & \frac{1}{1+(1-\gamma) \frac{R_{1}}{\gamma \mathbb{E}\left[R_{2} \mid(p \cdot \eta)_{H}\right]-(p \cdot \eta)_{H} R_{2}}},
\end{aligned}
$$

simplify to get

$$
\begin{aligned}
&\left\{\frac{-\gamma \pi \mathbb{E}\left[R_{2} \mid(p \cdot \eta)_{L}\right]+\gamma \pi \mathbb{E}\left[R_{2} \mid(p \cdot \eta)_{H}\right]+\pi \mathbb{E}\left[R_{2} \mid(p \cdot \eta)_{L}\right]-\pi \mathbb{E}\left[R_{2} \mid(p \cdot \eta)_{H}\right]}{\gamma R_{1}-R_{1}+(p \cdot \eta)_{H} R_{2}-\gamma \pi \mathbb{E}\left[R_{2} \mid(p \cdot \eta)_{H}\right]-\gamma \mathbb{E}\left[R_{2} \mid(p \cdot \eta)_{L}\right]+\gamma \pi \mathbb{E}\left[R_{2} \mid(p \cdot \eta)_{L}\right]}\right. \\
&\left.+\frac{-\gamma \mathbb{E}\left[R_{2} \mid(p \cdot \eta)_{H}\right]-\mathbb{E}\left[R_{2} \mid(p \cdot \eta)_{L}\right]+\gamma \mathbb{E}\left[R_{2} \mid(p \cdot \eta)_{L}\right]+\mathbb{E}\left[R_{2} \mid(p \cdot \eta)_{H}\right]}{\gamma R_{1}-R_{1}+(p \cdot \eta)_{H} R_{2}-\gamma \pi \mathbb{E}\left[R_{2} \mid(p \cdot \eta)_{H}\right]-\gamma \mathbb{E}\left[R_{2} \mid(p \cdot \eta)_{L}\right]+\gamma \pi \mathbb{E}\left[R_{2} \mid(p \cdot \eta)_{L}\right]}\right\} \\
& \cdot \frac{\gamma R_{1}}{-\gamma \mathbb{E}\left[R_{2} \mid(p \cdot \eta)_{H}\right]+(p \cdot \eta)_{H} R_{2}+\gamma R_{1}-R_{1}} \\
&>0 .
\end{aligned}
$$

It can be seen that

$$
\begin{aligned}
& -\gamma \mathbb{E}\left[R_{2} \mid(p \cdot \eta)_{H}\right]+(p \cdot \eta)_{H} R_{2}+\gamma R_{1}-R_{1} \\
= & \gamma\left(R_{1}-\mathbb{E}\left[R_{2} \mid(p \cdot \eta)_{H}\right]\right)+\left((p \cdot \eta)_{H} R_{2}-R_{1}\right) \\
< & 0
\end{aligned}
$$

as well as

$$
\begin{aligned}
& \gamma R_{1}-R_{1}+(p \cdot \eta)_{H} R_{2}-\gamma \pi \mathbb{E}\left[R_{2} \mid(p \cdot \eta)_{H}\right]-\gamma \mathbb{E}\left[R_{2} \mid(p \cdot \eta)_{L}\right]+\gamma \pi \mathbb{E}\left[R_{2} \mid(p \cdot \eta)_{L}\right] \\
= & R_{1}(\gamma-1)+\left((p \cdot \eta)_{H} R_{2}-\gamma \mathbb{E}\left[R_{2} \mid(p \cdot \eta)_{L}\right]\right)+\gamma \pi\left(\mathbb{E}\left[R_{2} \mid(p \cdot \eta)_{L}\right]-\mathbb{E}\left[R_{2} \mid(p \cdot \eta)_{H}\right]\right) \\
< & 0
\end{aligned}
$$

since each term is negative. What's more,

$$
-\gamma \pi \mathbb{E}\left[R_{2} \mid(p \cdot \eta)_{L}\right]+\gamma \pi \mathbb{E}\left[R_{2} \mid(p \cdot \eta)_{H}\right]+\pi \mathbb{E}\left[R_{2} \mid(p \cdot \eta)_{L}\right]-\pi \mathbb{E}\left[R_{2} \mid(p \cdot \eta)_{H}\right]
$$




$$
\begin{aligned}
& -\gamma \mathbb{E}\left[R_{2} \mid(p \cdot \eta)_{H}\right]-\mathbb{E}\left[R_{2} \mid(p \cdot \eta)_{L}\right]+\gamma \mathbb{E}\left[R_{2} \mid(p \cdot \eta)_{L}\right]+\mathbb{E}\left[R_{2} \mid(p \cdot \eta)_{H}\right] \\
= & (1-\pi)(1-\gamma)\left(\mathbb{E}\left[R_{2} \mid(p \cdot \eta)_{H}\right]-\mathbb{E}\left[R_{2} \mid(p \cdot \eta)_{L}\right]\right) \\
> & 0
\end{aligned}
$$

since each term is positive. Given that the sign of each part of inequality (A.1)'s left hand side has been determined, it's easily seen that inequality (A.1) indeed holds.

To show that $d_{0, T} \geq \mathbb{E}\left[R\left(\alpha_{H}, c\right)\right]=\pi d_{0}+(1-\pi) c$, we only have to show

$$
d_{0, T}-\pi d_{0}+(1-\pi) c \geq 0
$$

Define the left hand side of inequality (A.4) as a function of $c$, i.e.

$$
g(c)=d_{0, T}-\pi d_{0}+(1-\pi) c
$$

Insert the expressions for $d_{0, T}$ and $d_{0}$, and evaluate $g(c)$ at $c=0$ and $c=R_{1}$ respectively, one can get

$$
\begin{aligned}
g(0)= & -\frac{1}{-\gamma \mathbb{E}\left[R_{2} \mid(p \cdot \eta)_{H}\right]+(p \cdot \eta)_{H} R_{2}+\gamma R_{1}-R_{1}} \\
& \cdot \frac{1}{\gamma R_{1}-R_{1}+(p \cdot \eta)_{H} R_{2}-\gamma \pi \mathbb{E}\left[R_{2} \mid(p \cdot \eta)_{H}\right]-\gamma \mathbb{E}\left[R_{2} \mid(p \cdot \eta)_{L}\right]+\gamma \pi \mathbb{E}\left[R_{2} \mid(p \cdot \eta)_{L}\right]} \\
& \cdot\left(-R_{1}^{2} \gamma \mathbb{E}\left[R_{2} \mid(p \cdot \eta)_{L}\right]+\pi^{2} \gamma^{2} R_{1} \mathbb{E}^{2}\left[R_{2} \mid(p \cdot \eta)_{H}\right]+R_{1}^{2} \gamma(p \cdot \eta)_{H} R_{2}-R_{1} \gamma(p \cdot \eta)_{H}^{2} R_{2}^{2}\right. \\
& +R_{1}^{2} \gamma \mathbb{E}\left[R_{2} \mid(p \cdot \eta)_{L}\right] \pi-\pi^{2} \gamma^{2} R_{1}(p \cdot \eta)_{H} R_{2} \mathbb{E}\left[R_{2} \mid(p \cdot \eta)_{H}\right]+2 \pi \gamma^{2} R_{1} \mathbb{E}\left[R_{2} \mid(p \cdot \eta)_{H}\right] \\
& \cdot \mathbb{E}\left[R_{2} \mid(p \cdot \eta)_{L}\right]+\pi \gamma^{2} R_{1}^{2}(p \cdot \eta)_{H} R_{2}-\pi \gamma R_{1}^{2}(p \cdot \eta)_{H} R_{2}-R_{1} \gamma \mathbb{E}\left[R_{2} \mid(p \cdot \eta)_{L}\right] \pi(p \cdot \eta)_{H} R_{2} \\
& +R_{1} \gamma \mathbb{E}\left[R_{2} \mid(p \cdot \eta)_{L}\right] \pi(p \cdot \eta)_{H} R_{2}+\pi \gamma R_{1}(p \cdot \eta)_{H}^{2} R_{2}^{2}-\pi \gamma^{2} R_{1}(p \cdot \eta)_{H} R_{2} \mathbb{E}\left[R_{2} \mid(p \cdot \eta)_{L}\right] \\
& +\pi^{2} \gamma^{2} R_{1}(p \cdot \eta)_{H} R_{2} \mathbb{E}\left[R_{2} \mid(p \cdot \eta)_{L}\right]-\pi^{2} \gamma^{2} R_{1} \mathbb{E}\left[R_{2} \mid(p \cdot \eta)_{H}\right] \mathbb{E}\left[R_{2} \mid(p \cdot \eta)_{L}\right] \\
& -R_{1} \gamma^{2} \mathbb{E}^{2}\left[R_{2} \mid(p \cdot \eta)_{H}\right] \pi+R_{1} \gamma^{2}(p \cdot \eta)_{H} R_{2} \mathbb{E}\left[R_{2} \mid(p \cdot \eta)_{H}\right]-R_{1}^{2} \gamma^{2} \mathbb{E}\left[R_{2} \mid(p \cdot \eta)_{L}\right] \pi \\
& \left.-R_{1}^{2} \gamma^{2}(p \cdot \eta)_{H} R_{2}-R_{1} \gamma^{2} \mathbb{E}\left[R_{2} \mid(p \cdot \eta)_{L}\right] \mathbb{E}\left[R_{2} \mid(p \cdot \eta)_{H}\right]+R_{1}^{2} \gamma^{2} \mathbb{E}\left[R_{2} \mid(p \cdot \eta)_{L}\right]\right) .
\end{aligned}
$$

Inequality (A.2) shows that the first term, $-\frac{1}{-\gamma \mathbb{E}\left[R_{2} \mid(p \cdot \eta)_{H}\right]+(p \cdot \eta)_{H} R_{2}+\gamma R_{1}-R_{1}}$, is positive, and Inequality (A.3) shows that the second term,

$$
\frac{1}{\gamma R_{1}-R_{1}+(p \cdot \eta)_{H} R_{2}-\gamma \pi \mathbb{E}\left[R_{2} \mid(p \cdot \eta)_{H}\right]-\gamma \mathbb{E}\left[R_{2} \mid(p \cdot \eta)_{L}\right]+\gamma \pi \mathbb{E}\left[R_{2} \mid(p \cdot \eta)_{L}\right]},
$$


is negative. Further, the fact that $\pi \geq \bar{\pi}_{2}=\frac{\gamma \mathbb{E}\left[R_{L}\right]-c}{\gamma \mathbb{E}\left[R_{H}\right]-c}$ implies that the third term is non-positive as well. Therefore, $g(0) \geq 0$.

Similarly, when $c=R_{1}$

$$
\begin{aligned}
g\left(R_{1}\right)= & -\frac{1}{-\gamma \mathbb{E}\left[R_{2} \mid(p \cdot \eta)_{H}\right]+(p \cdot \eta)_{H} R_{2}+\gamma R_{1}-R_{1}} \\
& \cdot \frac{1}{\gamma R_{1}-R_{1}+(p \cdot \eta)_{H} R_{2}-\gamma \pi \mathbb{E}\left[R_{2} \mid(p \cdot \eta)_{H}\right]-\gamma \mathbb{E}\left[R_{2} \mid(p \cdot \eta)_{L}\right]+\gamma \pi \mathbb{E}\left[R_{2} \mid(p \cdot \eta)_{L}\right]} \\
& \cdot\left(-2 R_{1}^{2} \gamma \mathbb{E}\left[R_{2} \mid(p \cdot \eta)_{L}\right]+2 \pi^{2} \gamma^{2} R_{1} \mathbb{E}^{2}\left[R_{2} \mid(p \cdot \eta)_{H}\right]+2 R_{1}^{2}(p \cdot \eta)_{H} R_{2}-2 R_{1}^{3} \pi \gamma\right. \\
& +R_{1} \pi(p \cdot \eta)_{H}^{2} R_{2}^{2}-R_{1}^{2} \gamma(p \cdot \eta)_{H} R_{2}-R_{1} \gamma(p \cdot \eta)_{H}^{2} R_{2}^{2}+3 R_{1}^{2} \gamma \pi \mathbb{E}\left[R_{2} \mid(p \cdot \eta)_{L}\right] \\
& +R_{1}^{3} \pi \gamma^{2}+R_{1}^{2} \gamma^{2} \mathbb{E}\left[R_{2} \mid(p \cdot \eta)_{H}\right]-R_{1}^{2} \mathbb{E}\left[R_{2} \mid(p \cdot \eta)_{H}\right] \gamma-\pi^{2} \gamma^{2} R_{1} R_{2}(p \cdot \eta)_{H} \\
& \cdot \mathbb{E}\left[R_{2} \mid(p \cdot \eta)_{H}\right]+4 \pi \gamma^{2} R_{1} \mathbb{E}\left[R_{2} \mid(p \cdot \eta)_{H}\right] \mathbb{E}\left[R_{2} \mid(p \cdot \eta)_{L}\right]+R_{1} \gamma^{2} \mathbb{E}\left[R_{2} \mid(p \cdot \eta)_{L}\right] \pi^{2} \\
& -R_{1}^{3} \gamma^{2}-R_{1}^{2} \gamma^{2} \pi^{2} \mathbb{E}\left[R_{2} \mid(p \cdot \eta)_{H}\right]+R_{1} R_{2} \gamma(p \cdot \eta)_{H} \mathbb{E}\left[R_{2} \mid(p \cdot \eta)_{H}\right]+\pi \gamma^{2} R_{1}^{2} R_{2}(p \cdot \eta)_{H} \\
& +\pi \gamma R_{1}^{2} R_{2}(p \cdot \eta)_{H}-3 R_{1} R_{2} \gamma \pi(p \cdot \eta)_{H} \mathbb{E}\left[R_{2} \mid(p \cdot \eta)_{L}\right]+2 R_{1} R_{2} \gamma(p \cdot \eta)_{H} \mathbb{E}\left[R_{2} \mid(p \cdot \eta)_{L}\right] \\
& +\pi \gamma R_{1} R_{2}^{2}(p \cdot \eta)_{H}^{2}-\pi \gamma^{2} R_{1} R_{2}(p \cdot \eta)_{H} \mathbb{E}\left[R_{2} \mid(p \cdot \eta)_{L}\right]+\pi^{2} \gamma^{2} R_{1} R_{2}(p \cdot \eta)_{H} \mathbb{E}\left[R_{2} \mid(p \cdot \eta)_{L}\right] \\
& -2 \pi^{2} \gamma^{2} R_{1} \mathbb{E}\left[R_{2} \mid(p \cdot \eta)_{H}\right] \mathbb{E}\left[R_{2} \mid(p \cdot \eta)_{L}\right]+2 R_{1}^{3} \gamma-R_{1} R_{2}^{2}(p \cdot \eta)_{H}^{2}-R_{1}^{3}+R_{1} R_{2} \gamma \\
& \cdot \pi^{2}(p \cdot \eta)_{H} \mathbb{E}\left[R_{2} \mid(p \cdot \eta)_{L}\right]-R_{1} R_{2} \gamma \pi^{2}(p \cdot \eta)_{H} \mathbb{E}\left[R_{2} \mid(p \cdot \eta)_{H}\right]-2 R_{1} \gamma^{2} \pi \mathbb{E}^{2}\left[R_{2} \mid(p \cdot \eta)_{H}\right] \\
& +R_{1} R_{2} \gamma^{2}(p \cdot \eta)_{H} \mathbb{E}\left[R_{2} \mid(p \cdot \eta)_{H}\right]+R_{1}^{3} \pi-2 R_{1}^{2} R_{2} \pi(p \cdot \eta)_{H}-R_{1}^{2} \gamma \pi^{2} \mathbb{E}\left[R_{2} \mid(p \cdot \eta)_{L}\right] \\
& +R_{1}^{2} \pi^{2} \gamma \mathbb{E}\left[R_{2} \mid(p \cdot \eta)_{H}\right]-3 R_{1}^{2} \gamma^{2} \pi \mathbb{E}\left[R_{2} \mid(p \cdot \eta)_{L}\right]-R_{1}^{2} R_{2} \gamma^{2}(p \cdot \eta)_{H}-2 R_{1} \gamma^{2} \\
& \left.\cdot \mathbb{E}\left[R_{2} \mid(p \cdot \eta)_{H}\right] \mathbb{E}\left[R_{2} \mid(p \cdot \eta)_{L}\right]+2 R_{1}^{2} \gamma^{2} \mathbb{E}\left[R_{2} \mid(p \cdot \eta)_{L}\right]\right) .
\end{aligned}
$$

The first two terms are the same as those in $g(0)$, and the fact that $\pi \geq \bar{\pi}_{2}=$ $\frac{\gamma \mathbb{E}\left[R_{L}\right]-c}{\gamma \mathbb{E}\left[R_{H}\right]-c}$ implies that the third term is non-negative. Therefore, $g\left(R_{1}\right) \leq 0$.

Since $g(c)$ is continuous and monotone in $c$, then there exists a $c_{0} \in\left[0, R_{1}\right]$ such that $d_{0, T} \geq \mathbb{E}\left[R\left(\alpha_{H}, c\right)\right], \forall c \in\left[0, c_{0}\right]$.

\section{B Results of numerical simulations}

The following figures present numerical simulations for various regulatory schemes. 


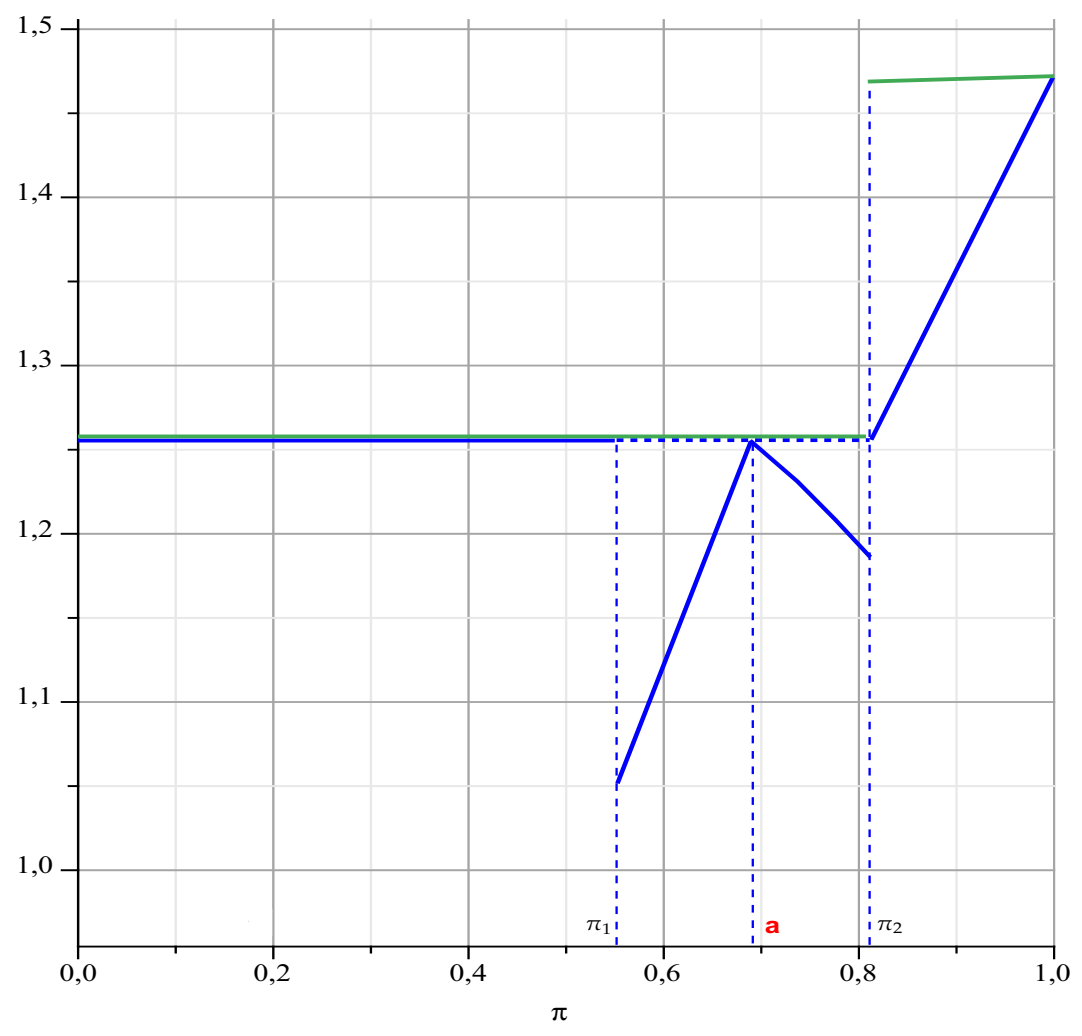

Fig. B.1. Investors' expected return in equilibrium: laissez-faire economy (solid blue line) versus economy with conditional liquidity injection \& procyclical taxation (solid green line). Parameter values: $(p \cdot \eta)_{H}=0.36,(p \cdot \eta)_{L}=0.24, \gamma=0.6, R_{1}=1.5$, $R_{2}=4, c=0.3, \bar{\eta}=0.8, \eta_{H}=0.9, \eta_{L}=0.6, \bar{p}=0.4, p_{H}=0.45, p_{L}=0.3, \sigma=0.5$.

\section{References}

Acharya, V. V. (2009): "A theory of systemic risk and design of prudential bank regulation". Journal of Financial Stability, 5, 224-255.

Acharya, V. V. ANd T. Yorulmazer (2008): “Cash-in-the-market pricing and optimal resolution of bank failures". Review of Financial Studies, 21, 27052742.

Allen, F., And D. Gale (1998): “Optimal financial crises". Journal of Finance, $53,1245-84$.

Bolton, P., T. Santos And J. A. Scheinkman (2009A): “Outside and inside liquidity". NBER Working paper 14867.

Bolton, P., T. Santos And J. A. Scheinkman (2009в): “Market and public 


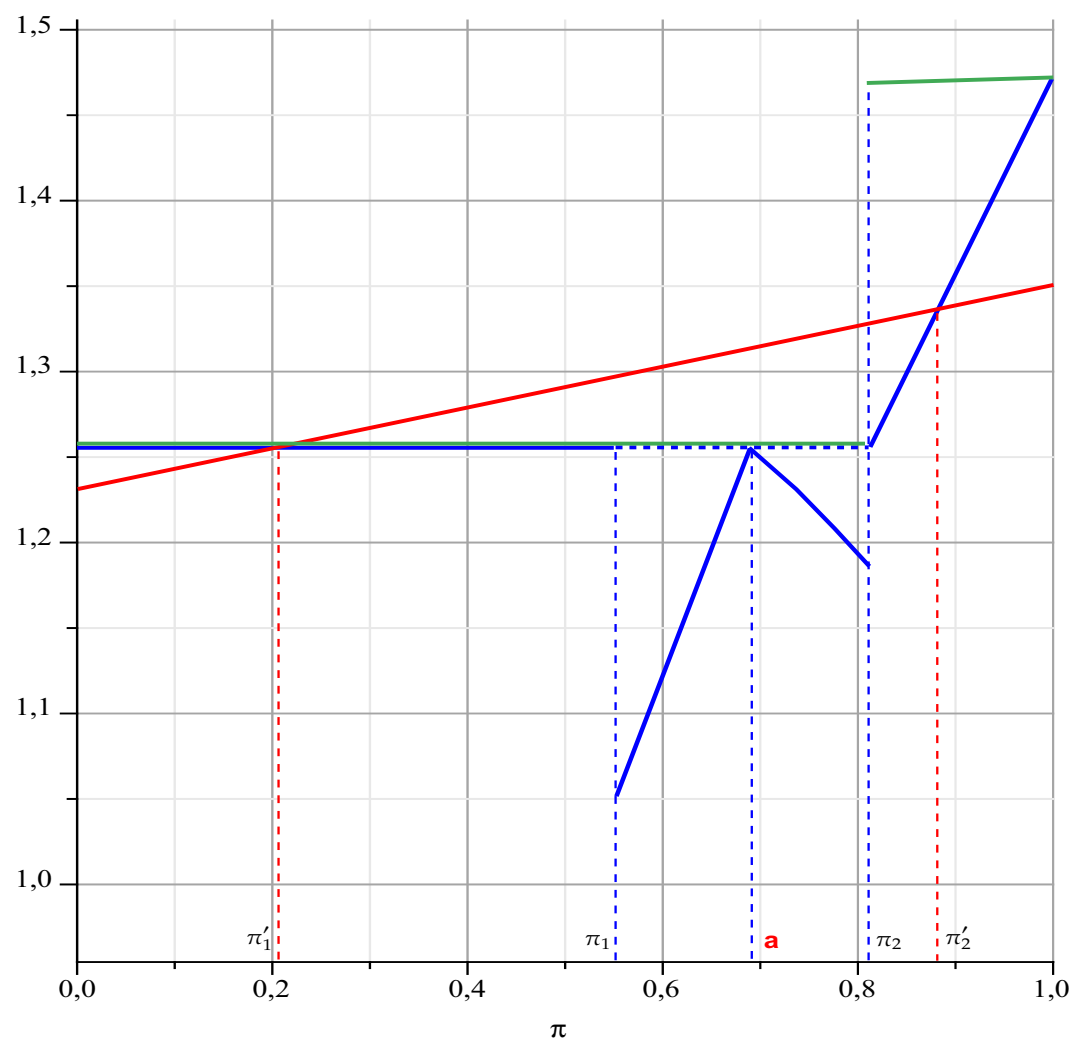

Fig. B.2. Investors' expected return in equilibrium: laissez-faire economy (solid blue line) versus economy with (1) equity requirement (solid red line) (2) conditional liquidity injection \& procyclical taxation (solid green line). Parameter values: $(p \cdot \eta)_{H}=0.36,(p \cdot \eta)_{L}=0.24, \gamma=0.6, R_{1}=1.5, R_{2}=4, c=0.3, \bar{\eta}=0.8, \eta_{H}=0.9$, $\eta_{L}=0.6, \bar{p}=0.4, p_{H}=0.45, p_{L}=0.3, \sigma=0.5, \zeta=0.5$. The outcome under equity requirement is superior to that of laissez-faire economy for $\pi \in\left[\bar{\pi}_{1}^{\prime}, \bar{\pi}_{2}^{\prime}\right]$.

liquidity". American Economic Review, 99, 594-599.

Brunnermeier, M. K., And L. H. Pedersen (2009): “Market liquidity and funding liquidity". Review of Financial Studies, 22, 2201-2238.

CaO, J. ANd G. Illing (2008): "Liquidity shortages and monetary policy". CESifo Working Paper Series No. 2210, available at SSRN: http://ssrn.com/ abstract $=1090825$.

CaO, J. And G. Illing (2009A): “Endogenous systemic liquidity risk". CESifo Working Paper Series No. 2627, available at SSRN: http://ssrn.com/ abstract $=1393186$.

CaO, J. and G. Illing (2009B): “Regulation of systemic liquidity risk”. Mimeo. 


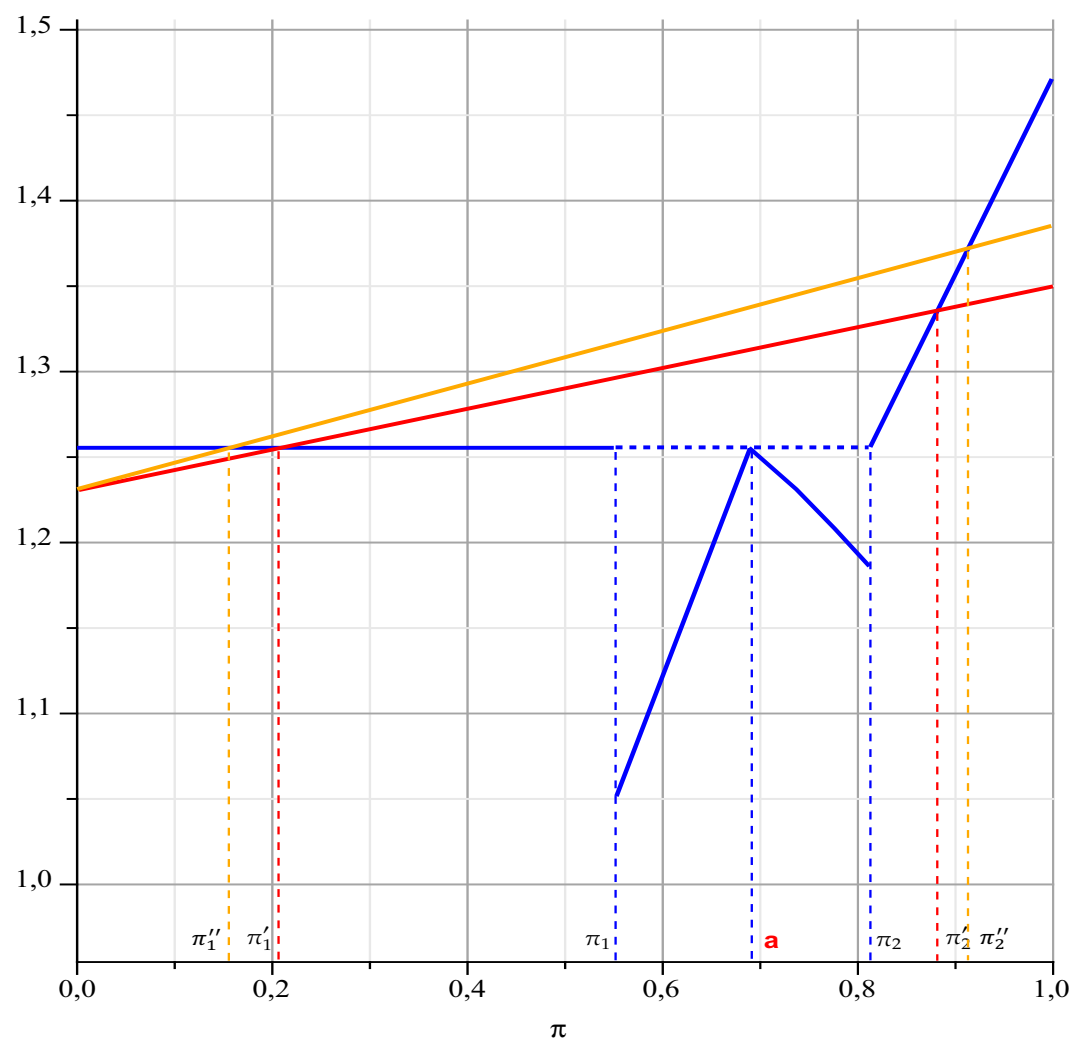

Fig. B.3. Investors' expected return in equilibrium: laissez-faire economy (solid blue line) versus economy with (1) pure equity requirement (solid red line) (2) equity requirement $\&$ liquidity regulation (solid orange line). Parameter values: $(p \cdot \eta)_{H}=0.36,(p \cdot \eta)_{L}=0.24, \gamma=0.6, R_{1}=1.5, R_{2}=4, c=0.3, \bar{\eta}=0.8, \eta_{H}=0.9$, $\eta_{L}=0.6, \bar{p}=0.4, p_{H}=0.45, p_{L}=0.3, \sigma=0.5, \zeta=0.5$. The outcome under equity requirement \& liquidity regulation is superior to that of laissez-faire economy for $\pi \in\left[\bar{\pi}_{1}^{\prime \prime}, \bar{\pi}_{2}^{\prime \prime}\right]$.

University of Munich.

Diamond, D. W. AND R. G. Rajan (2005): “Liquidity shortage and banking crises". Journal of Finance, 60, 30-53.

Diamond, D. W. And R. G. Rajan (2006): "Money in the theory of banking". American Economic Review, 60, 615-647.

Freixas, X., B. M. Parigi And J.-C. Rochet (2000): “Systemic risk, interbank relations, and liquidity provision by the central bank". Journal of Money, Credit and Banking, 32, 611-638.

Freixas, X., B. M. Parigi And J.-C. Rochet (2004): “The lender of last re- 


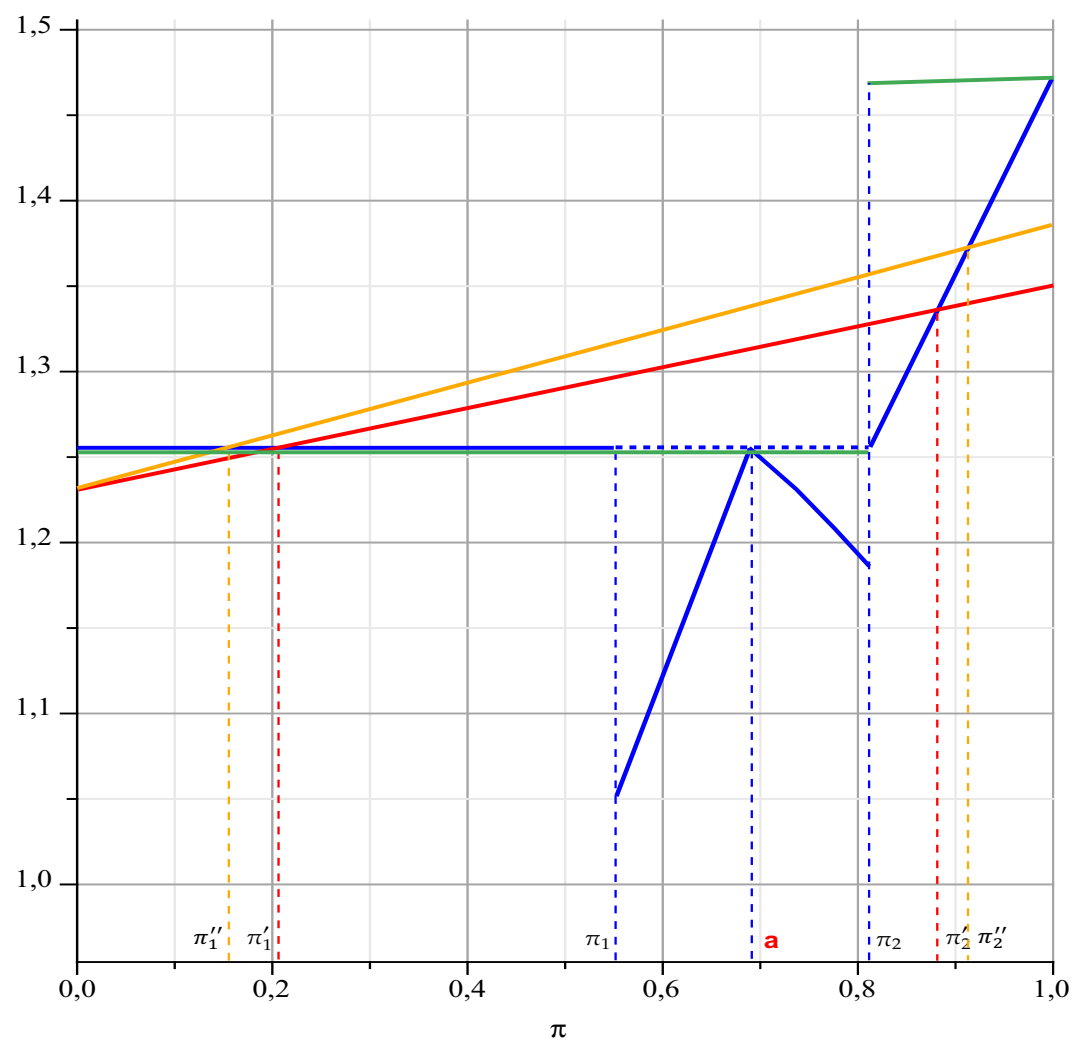

Fig. B.4. Investors' expected return in equilibrium: laissez-faire economy (solid blue line) versus economy with (1) conditional liquidity injection \& procyclical taxation (solid green line) (2) pure equity requirement (solid red line) (3) equity requirement \& liquidity regulation (solid orange line). Parameter values: $(p \cdot \eta)_{H}=0.36$, $(p \cdot \eta)_{L}=0.24, \gamma=0.6, R_{1}=1.5, R_{2}=4, c=0.3, \bar{\eta}=0.8, \eta_{H}=0.9, \eta_{L}=0.6, \bar{p}=0.4$, $p_{H}=0.45, p_{L}=0.3, \sigma=0.5, \zeta=0.5$.

sort: A twenty-first century approach". Journal of the European Economic Association, 2, 1085-1115.

Gorton, G. (2007): “Banks, banking, and crises". NBER Reporter, 2007 Number $4,11-14$.

Gorton, G. (2009): “The subprime panic”. European Financial Management, $15,10-46$.

Gorton, G. ANd L. Huang (2004): "Liquidity, efficiency, and bank bailouts". American Economic Review, 94, 455-483.

Holmström, B. And J. Tirole (1998): "Private and public supply of liquidity". Journal of Political Economy, 106, 1-40. 
Holmström, B. AND J. Tirole (2008): Wicksell lectures: Inside and outside liquidity. Mimeo. Toulouse School of Economics.

KorineK, A. (2008): "Systemic risk-taking: Accelerator effects, externalities, and regulatory responses". Mimeo. University of Maryland.

WAgner, W. (2009): "Efficient asset allocations in the banking sector and financial regulation". International Journal of Central Banking (forthcoming). 